\title{
DISTÚRBIOS DO TRATO RESPIRATÓRIO INFERIOR DE PEQUENOS RUMINANTES
}

\author{
DISORDERS OF THE LOWER RESPIRATORY TRACT OF SMALL RUMINANTS
}

\author{
Delia Lacasta $^{1 \oplus}$, Mario Felipe Alvarez Balaro ${ }^{2}$, Marta Borobia $^{1 \oplus}$, Aurora Ortín $^{1 \oplus}$, Lluís Luján ${ }^{1 \oplus}$, Héctor Ruiz ${ }^{1 \oplus}$, \\ Marta Ruiz de Arcaute $^{1 \oplus}$, Juan José Ramos Antón ${ }^{1}{ }^{\oplus}$, Luis Miguel Ferrer Mayayo ${ }^{1 \oplus}$
}

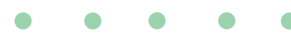

Serviço Clínico de Ruminantes ( SCRUM), Departamento de Patologia Animal, Universidade de Zaragoza, Espanha.

Departamento de Patologia e Clínica Veterinária, Faculdade de Veterinária, Universidade Federal Fluminense (UFF), Niterói, Rio de Janeiro, Brasil.

Autor para correspondência: delialacasta@gmail.com

Revista Brasileira de Buiatria Clínica Médica, Volume 1, Número 7, 2021

ISSN 2763-955X

DOI:10.4322/2763-955X.2021.007

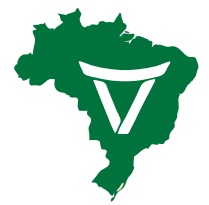

Associação Brasileira de Buiatria
RESUMO
O artigo objetiva revisar alguns dos distúrbios do trato respiratório inferior de maior ocorrência em pequenos ruminantes. Sua relevância no manejo sanitário está relacionada à queda no desempenho produtivo, mortalidade, redução do ganho de peso e qualidade da carcaça de cordeiros/cabritos produzidos, e aumento da taxa de descarte e reposição. Aqui, apresentamos a pneumonia por aspiração, complexo respiratório ovino (CRO), adenocarcinoma pulmonar ovino (APO), lentiviroses de pequenos ruminantes (LVPR), pneumonia parasitária e fúngica, assim como as formas pulmonares da linfadenite caseosa (LC) e das micoplasmoses. A pneumonia por aspiração é uma infecção comumente causada pela inalação de materiais estranhos, produzindo inflamação e necrose do parênquima pulmonar. O CRO é um processo que envolve uma variedade de interações hospedeiro-patógeno-ambiente, em que os mecanismos imunológicos e fisiológicos do hospedeiro interagem com vários agentes etiológicos, incluindo vírus, bactérias, além de fatores ambientais ou estressores. A forma pulmonar da LC comumente causa lesões nos linfonodos mediastinais e no parênquima pulmonar, produzindo sinais clínicos respiratórios, principalmente a tosse responsável pela transmissão da doença por aerossol. O APO é um câncer de pulmão, contagioso, causado pelo retrovírus jaagsiekte ovino, que induz a transformação de células epiteliais secretoras do trato respiratório distal. A afecção pulmonar pela LVPR é a forma de doença mais grave na espécie ovina. A infecção ocorre pelo contato direto entre animais e a via de infecção mais importante é pelo trato respiratório. A pneumonia parasitária e fúngica são menos frequentes, mas relevantes dentro do diagnóstico diferencial das enfermidades respiratórias. Dada a natureza multifacetada dessas doenças, as práticas de manejo (por exemplo, melhorias nas habitações, implementação de medidas de biossegurança e abate seletivo de animais infectados) precisam ser consideradas para sua prevenção; como as condições ambientais também desempenham um papel no desenvolvimento dessas doenças, elas devem ser levadas em consideração. Por fim, outras medidas sanitárias adequadas como protocolos vacinais contra alguns agentes visando a melhora na resposta imune animal também ajudam no controle destas doenças.

Palavras-chave: adenocarcinoma pulmonar ovino, complexo respiratório, lentivírus de pequenos ruminantes, pneumonia por aspiração, pneumonia parasitária e fúngica.

\section{ABSTRACT}

The article aims to review some of the lower respiratory tract disorders of major occurrence in small ruminants. Their relevance within the health management are related to the drop in productive performance, reduction in weight gain and quality of the carcass of lambs/kids produced, and increase in the mortality, culling and replacement rate. Herein we examine the aspiration pneumonia, ovine respiratory complex (ORC), ovine pulmonary adenocarcinoma (OPA), small ruminant lentiviruses (SRLV), parasitic and fungal pneumonia, as well as the pulmonary form of caseous lymphadenitis (CLA) and mycoplasmosis. Aspiration pneumonia is an infection commonly caused by inhalation of foreign materials, producing inflammation and necrosis of the lung parenchyma. The $\mathrm{ORC}$ is a process involving a range of host-pathogen-environment interactions, where host immunological and physiological mechanisms interact with multiple etiological agents including viruses, bacteria, plus environmental factors or stressors. Pulmonary form of CLA commonly causes lesions in mediastinal lymph nodes and lung parenchyma, producing respiratory clinical signs, particularly the coughing that is responsible for transmission of the disease by aerosol. OPA is a contagious lung cancer of sheep caused by jaagsiekte sheep retrovirus, which induces the transformation of secretory epithelial cells of the distal respiratory tract. Pulmonary affection due to SRLV is the most severe disease form in sheep species. The infection occurs by direct contact between animals and the most important infection routes are lactogenic and respiratory. Parasitic and fungal pneumonia are less frequent, but relevant in the differential diagnosis of respiratory diseases. Given the multi-faceted nature of these diseases, management practices (e.g., housing improvements, implementation of biosecurity provisions and selective culling of infected animals) need to be considered for their prevention; as environmental conditions also play a role in development of these diseases, they should be taken into account. Lastly, other appropriate health measures, such as vaccine protocols against some agents aiming at improving the animal immune response, also help in the control of these diseases. 


\section{INTRODUÇÃO}

As doenças respiratórias estão associadas a perdas econômicas significativas na produção de pequenos ruminantes. Sua importância depende não apenas do alto número de animais afetados e sua mortalidade, mas também das perdas indiretas associadas, como condenações de carcaças, tratamentos e diminuição da produção.

Em ovinos, as perdas econômicas relacionadas a pneumonia foram estudadas principalmente em sistemas de produção de cordeiros de corte. $\mathrm{Na}$ Espanha, foram estudadas as perdas diretas, associadas à mortalidade e condenações de carcaças, e as perdas indiretas, relacionadas aos tratamentos, diminuição do crescimento médio diário e má qualidade dos cordeiros produzidos. Concluiu-se que o custo final da pneumonia em cordeiros era $7 \%$ de seu valor ${ }^{1}$. Igualmente, este distúrbio foi a principal causa de morte em confinamentos atingindo 78,5\% (4234/5394) dos casos ${ }^{2}$. O transtorno ainda foi a principal causa de morte independentemente da região de criação, estação do ano, raça ou peso corporal ${ }^{2}$. Em frigoríficos neozelandeses, a frequência de lesões pulmonares e pleurisia chegaram a $28 \%$ (3212/11471) dos ovinos abatidos ${ }^{3}$. Índice semelhante ao encontrado na Espanha que mesmo entre cordeiros sem sinais clínicos respiratórios, a proporção de pulmões condenados foi de 34\%. Além disso, cordeiros sintomáticos apresentaram risco 3,1 vezes maior de condenação de pulmões do que os assintomáticos ${ }^{2}$. Ainda, a aparência das lesões pulmonares varia de acordo com as mudanças climáticas e microambientais ${ }^{4}$.

A associação entre a gravidade da pneumonia $\mathrm{e}$ o desempenho ponderal em cordeiros foi descrita. Constatou-se que quando mais de $20 \%$ da área da superfície pulmonar foi afetada pela pneumonia, o ganho de peso diminuiu de 136 para $65 \mathrm{~g} / \mathrm{dia}^{5}$. Igualmente, uma relação linear significativa entre o ganho de peso vivo e a extensão das lesões pneumônicas também já foi relatada indicando uma redução de quase 1 $\mathrm{kg} /$ mês para cada $10 \%$ de superfície pulmonar afetada ${ }^{6}$. Ainda, estudos conduzidos em confinamentos espanhóis também relacionaram as lesões pulmonares com consequências sobre o crescimento, taxa de conversão alimentar e qualidade da carcaça de cordeiros e identi-

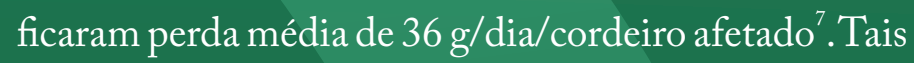
resultados causam um atraso de até $10 \%$ no tempo para que os cordeiros atinjam o peso ideal de abate. No mesmo contexto, cordeiros com lesões pulmonares e aderências pleurais possuíram diferenças de catorze e 33 dias, respectivamente, a mais necessários para atingirem o peso de abate. ${ }^{8}$. Os dias estendidos para o abate aumentam a quantidade de investimento necessário, pois a duração da engorda é prolongada, o que leva a atrasos nos retornos; custos de trabalho mais elevado e maior risco de morte por outras causas. ${ }^{2}$ Por fim, as doenças respiratórias em cordeiros podem depreciar a qualidade do produto final, devido à redução da gordura que dificulta as vendas e resulta em menor preço das carcaças.

A importância do complexo respiratório ovino $(\mathrm{CRO})$ nas produções intensivas a semi-intensivas de ovinos na Espanha vem sendo descrita. Em um deles realizado na maior propriedade de ovinos leiteiros do país, com mais de 13.000 ovinos Lacaune manejados em sistema intensivo, foram acompanhadas as causas de óbito do rebanho em um período de dois meses e meio. Foram realizadas 175 necropsias de animais adultos em que o CRO foi o segundo maior motivo de morte (23\% de todos os casos), após os problemas reprodutivos (27\%). As infecções por lentivírus de pequenos ruminantes (LVPR) e adenocarcinoma pulmonar ovino (APO) foram responsáveis por 4,5\% dos casos. Quando estes foram associados ao CRO, as doenças respiratórias tornaram-se o principal motivo de óbito ${ }^{9}$. Relatos semelhantes foram descritos em ovinos leiteiros na Argentina ${ }^{10}$. Ainda, em um rebanho de ovinos de corte, manejado em sistema semiextensivo na Espanha, a taxa média de mortalidade em animais adul- 
tos foi de $8 \%$, sendo o CRO o principal motivo de morte em um período de quatro anos ${ }^{9}$. Finalmente, em um estudo com 195 ovelhas abatidas, junto aos dados clínicos e exame post mortem, foram detectadas lesões pulmonares em 60,5\% (118/195) dos animais. Lesões supurativas ou fibrinosas, ambas associadas ao $\mathrm{CRO}$, foram responsáveis por $27,1 \%(32 / 118)$ do total de lesões encontradas ${ }^{9}$. Lesões de pneumonia intersticial associada a infecções por LVPR foram detectadas em $24,6 \%$ (29/118) dos animais e 62\% (18/29) destes também possuíam lesões associadas a outros agentes etiológicos ${ }^{9}$. Tal resultado ratifica a importância das coinfecções pulmonares, especialmente porque infecções por LVPR que podem predispor a infecções por outros agentes ${ }^{11}$.

No Brasil, o impacto econômico das doenças pulmonares em pequenos ruminantes ainda é pouco estudado e os relatos variam de acordo com as regiões do país. No Pará, verificou-se que 7\% das enfermidades em sistemas de produção eram decorrentes de problemas respiratórios ${ }^{12}$. Em Minas Gerais e Mato Grosso do Sul, foram descritos 10,5\% (6/57) e 11,7\% (21/180) de doenças pulmonares, respectivamente, em ovinos necropsiados em centros universitários ${ }^{13,14}$. Nestes estudos foram observados casos de pleuropneumonias, broncopneumonias e pneumonias fibrinonecrosantes, associados principalmente a Mannheimia haemolytica, assim como em surtos em rebanhos ovinos do Rio Grande do Sul e Minas Gerais, com morbidade de $25 \%(\mathrm{RS})$ e mortalidade de $1,7 \%(10 / 600 ; \mathrm{MG})^{15,16}$. Bactérias gram-negativas não fermentadoras, Bacillus sp.e microrganismos da classe Mollicutes (Mycoplasma mycoides subsp.capri) também podem levar a processos pneumônicos na espécie ovina ${ }^{17}$.

Em caprinos, tem sido relatada uma frequência de 2,6\% (3/114) a 10,3\% (20/290) de doenças pulmonares em necropsias realizadas no Rio Grande do $\mathrm{Sul}^{18,19}$. Igualmente, surtos de mannheimiose caprina vêm sendo relatados atingindo taxas de mortalidade entre $3,3 \%(9 / 276)$ a $9 \%(26 / 290)$ e letalidade de $90 \%$, sendo estes associados a fatores predisponentes estressantes como transporte prolongado, época do ano e mudanças ambientais ${ }^{19,20}$.

Com relação aos agentes virais, frequências de anticorpos contra o Vírus Parainfluenza tipo 3 (PI-3) e Vírus Sincicial Respiratório (VSR), tem variado entre $52,5 \%(52 / 99)$ e $81,9 \%(159 / 194)$ e entre $48,5 \%$ (48/99) e 58,8\% (114/194), respectivamente, em ovinos sadios e enfermos. Tais estudos não encontraram associação entre a presença de anticorpos e desordens respiratórias nos soropositivos ${ }^{21,22}$. Entretanto, infecções pelo PI-3, VSR e adenovírus podem predispor a infecção por $M$. baemolytica ${ }^{15,23,24}$. Em resumo, a infecção pelo PI-3 promove um microambiente pulmonar de células necróticas e fluido proteináceo que favorece o crescimento bacteriano. Igualmente, o PI-3 se replica em macrófagos e pode induzir a redução da fagocitose e da sua função bactericida ${ }^{24}$.

Com base no exposto, verifica-se o impacto econômico das enfermidades respiratórias de vias baixas em diversos países que possuem destaque internacional na produção de ovinos. No Brasil, os relatos ainda são escassos e concentram-se principalmente na descrição clínica de surtos ou inquéritos sorológicos/microbiológicos na temática. Deste modo, são necessários avanços no conhecimento epidemiológico e econômico destes agentes e enfermidades para a pecuária ovina e caprina no país.

\section{APRESENTAÇÃO CLÍNICA E DIAGNÓSTICO DIFERENCIAL}

Diversos microorganismos podem se instalar e lesionar as vias aéreas inferiores de ruminantes devido a sua anatomia e fisiologia particular, o que acarreta num amplo e variado diagnóstico diferencial destas enfermidades. Tal fato, aliado à intensa variabilidade na apresentação dos sinais clínicos respiratórios e restrição semiológica da região torácica, tornam o diagnóstico difícil. Assim, a maioria das doenças que se instalam no 
pulmão produzem sinais clínicos similares. Taquipneia e dispneia expiratória ou mista são sinais clínicos comuns de todas as doenças. Igualmente, a respiração pela boca, narinas dilatadas (Figura 1) e posição ortopneica (Figura 2) caracterizam quadros mais graves. Para diagnosticar o distúrbio que está afetando o animal, é fundamental realizar um exame clínico completo do sistema respiratório e, muitas vezes, associado a exames complementares.

Neste contexto, a ultrassonografia possui grande relevância para o diagnóstico in vivo de enfermidades do trato respiratório inferior, pois a maioria dos processos pode ser diferenciada por meio desta técnica de imagem ${ }^{25}$. Ainda, o lavado traqueobrônquico (LTB) e broncoalveolar (LBA) também devem ser considerados como importantes componentes na abordagem diagnóstica, pois ajudam na precisão do diagnóstico e na identificação dos agentes causais ${ }^{26,27}$. Nesta revisão, em especial, iremos dar enfoque no diagnóstico post mortem necroscópico.

Após detectar que um animal tem dispneia, é preciso distinguir se o processo é produtivo ou não produtivo. Para diferencia-los, a tosse deve ser provocada e o pulmão cuidadosamente auscultado. Se a tosse for produtiva e houver ruídos adventícios, como roncos ou crepitações, estaremos diante de um processo respiratório produtivo. Neste caso, o diagnóstico diferencial é
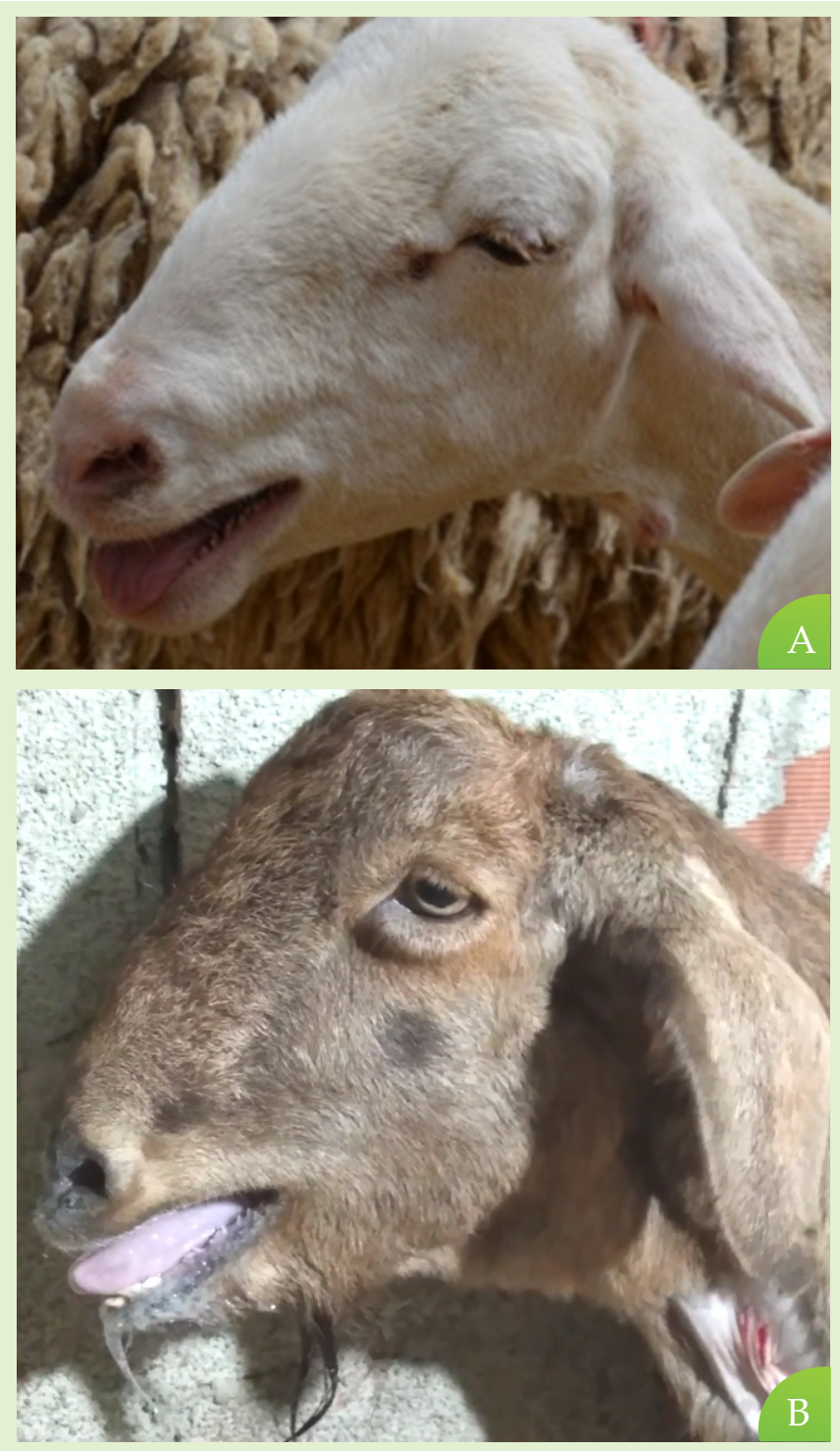

Figura 1. Pequenos ruminantes em angústia respiratória aguda com respiração pela boca e narinas dilatadas.

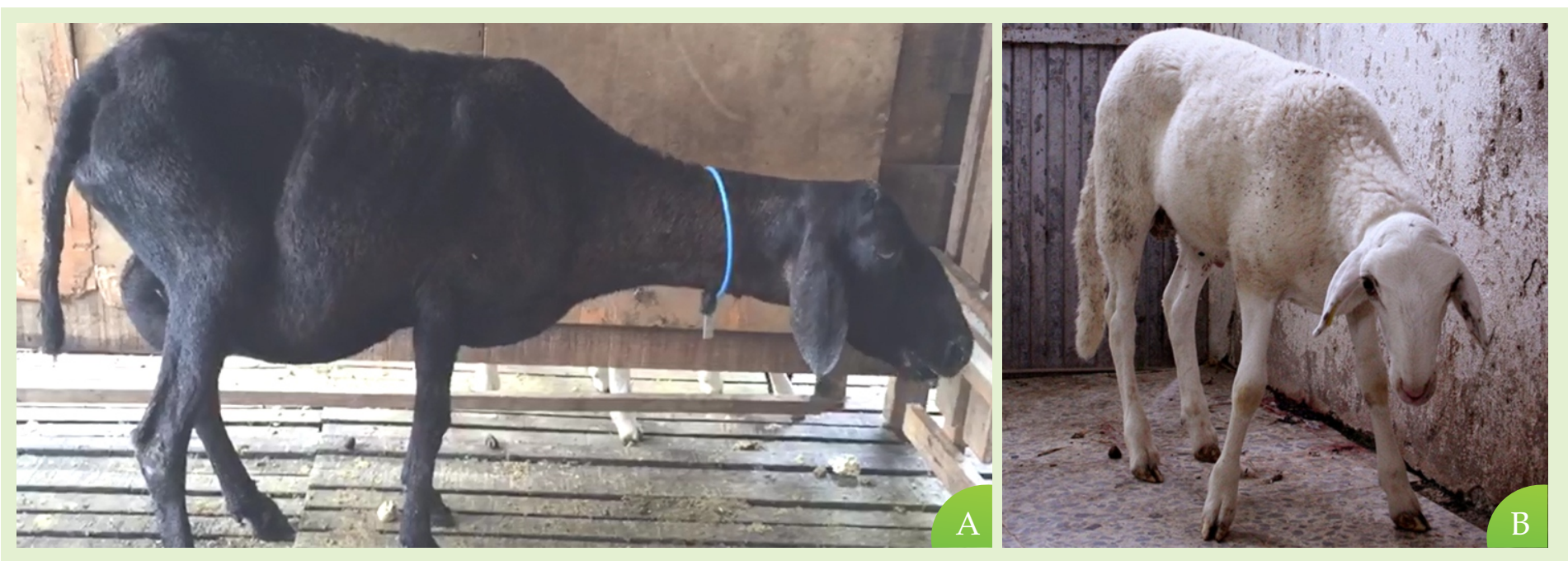

Figura 2. Ovinos em posição ortopneica com a cabeça e pescoço estendidos, abdução de membros anteriores e narinas dilatadas. 
Dispneia Mista / Expiratória

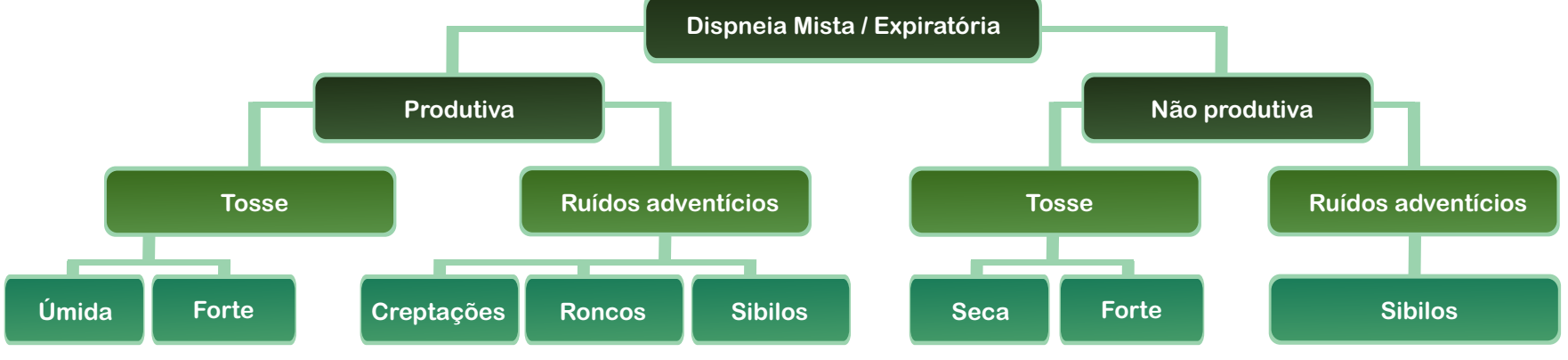
Clínica produtiva

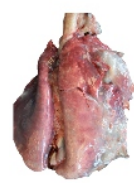

Pneumonia aspirativa
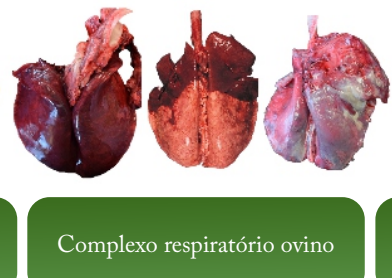

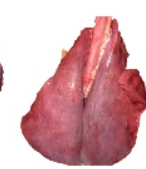

Língua azul
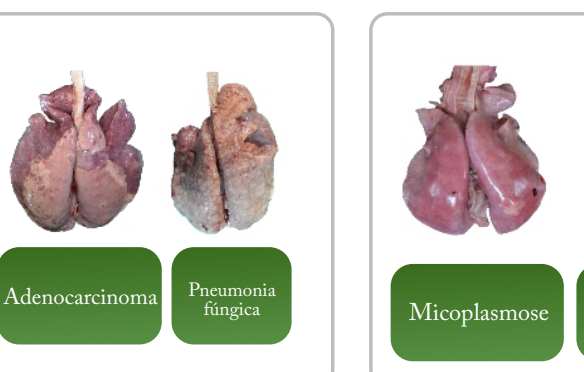
Clínica não produtiva
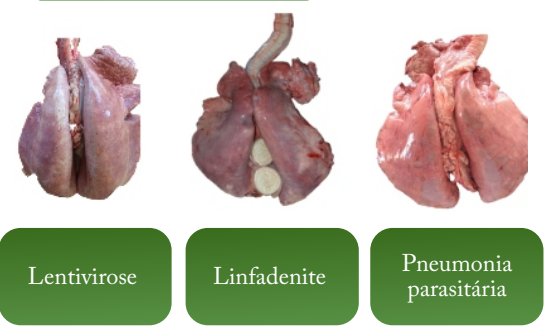

Figura 3. Compilado dos achados clínicos em infecções pulmonares produtivas e não produtivas junto ao diagnóstico diferencial das principais enfermidades envolvidas.

baseado em cinco quadros principais: APO, CRO, língua azul, pneumonia por aspiração ou pneumonia fúngica (Figura 3). Inicialmente, para o APO, indicase o teste do "carrinho de mão" e, se for negativo, descartamos o APO clínico (com risco de não detectar uma forma inicial ou atípica da doença). Da mesma forma, o mau odor do ar exalado pode ajudar a diagnosticar a pneumonia por aspiração.

A ausculta e o diagnóstico de distúrbios respiratórios não produtivos, como a pneumonia intersticial relacionada às parasitoses, lentiviroses, micoplasmoses, ou pneumonia abscedativa devido a Corynebacterium pseudotuberculosis (linfadenite caseosa) ou ainda por Trueperella pyogenes, são difíceis. Nestes casos, a dispneia pode estar associada ou não a tosse seca e ruídos adventícios como sibilos (Figura 3). Novamente, a ultrassonografia, LTB e LBA são essenciais no direcionamento do diagnóstico in vivo.

Por fim, é importante ressaltar que determinadas enfermidades possuem frequências distintas de acordo com a fase produtiva na qual o animal se encontra (Figura 4). A seguir, serão abordadas as principais doenças que afetam o trato respiratório inferior em pequenos ruminantes, agrupando-os em processos produtivos e não produtivos.

\section{Cria e recria}

N.o de afetados

Curso clínico

$\begin{array}{lllll}\text { Individual } & \text { Coletivo } & \text { Súbito } & \text { Agudo } & \text { Crônico } \\ \text { Língua azul } & \text { CRO } & \text { CRO } & \text { CRO } & \text { CRO } \\ \text { P. por aspiração } & \text { Língua azul } & \text { Língua azul } & \text { Língua azul } & \text { P. aspiração } \\ & \text { P. fúngica } & & \text { P. fúngica } & \text { P. parasitária } \\ & \text { P. parasitária } & & \text { P. por aspiração }\end{array}$

\section{Adultos}

N.ㅇ de afetados

Curso clínico

\begin{tabular}{|c|c|c|c|c|}
\hline Individual & Coletivo & Súbito & Agudo & Crônico \\
\hline APO & CRO & CRO & CRO & APO \\
\hline CRO & LVPR & & P. por aspiração & CRO \\
\hline P. por aspiração & LC pulmonar & & & LVPR \\
\hline & P. parasitária & & & $\begin{array}{l}\text { LC pulmonar } \\
\text { P. parasitária } \\
\text { P. por aspiraçãa }\end{array}$ \\
\hline
\end{tabular}

Periparto e lactantes
N. de afetados

Individual Coletivo

CRO

Língua azul Língua azul

P. por aspiração

\section{Curso clínico}

Súbito Agudo Crônico

CRO CRO CRO
Língua azul Língua azul P. por aspiração

Figura 4. Esquema do número de afetados (individual ou coletivo) e curso clínico (súbito, agudo ou crônico) das afecções pulmonares de acordo com a fase produtiva (cria e recria, adultos, periparto e lactantes) no sistema de produção de pequenos ruminantes. 


\section{DOENÇAS QUE CURSAM COM PROCESSO PRODUTIVO}

\section{- Complexo Respiratório Ovino (CRO)}

O principal processo bacteriano respiratório que afeta pequenos ruminantes era tradicionalmente descrito como "pasteurelose", refletindo que as bactérias da família Pasteurellaceae estavam predominantemente envolvidas. Outros nomes associados a esta doença são pneumonia enzoótica ou pneumonia atípica. No entanto, as semelhanças da "pasteurelose" no adulto com o $\mathrm{CRO}$ em animais jovens, sugerem que a primeira seja englobada dentro do CRO.

$\mathrm{O} C R O$ afeta tanto animais jovens quanto adultos, embora em jovens seja geralmente uma doença primária e, em adultos, geralmente é secundária a outros distúrbios. É um processo que envolve uma gama de interações hospedeiro-patógeno-ambiente (HPE), onde os mecanismos imunológicos e fisiológicos (hospedeiro) interagem com diversos agentes etiológicos (patógenos) dentro de um contexto ambiental e,presença ou não, de estressores (ambiente).
Fatores ambientais têm se mostrado críticos no desenvolvimento desta doença, portanto, a influência do clima e das instalações onde os animais são alojados tem sido amplamente relatada ${ }^{4,28,29}$. Vários agentes infecciosos estão associados com o $\mathrm{CRO}$, sendo os mais importantes: M. haemolytica, Pasteurella multocida, Bibersteinia trehalosi e Mycoplasma spp., cada um deles com seus diversos sorotipos. Destes, é mais frequente o isolamento B. threalosi em casos hiperagudos (súbitos), M. haemolytica em quadros agudos e P. multocida e Mycoplasma spp. nas formas crônicas da doença, sendo também comum isolamentos mistos ${ }^{30}$. É importante ressaltar que a maioria destas bactérias é da microbiota comensal da nasofaringe, tonsila e pulmões de animais saudáveis e, em certas circunstâncias de imunossupressão ou oportunismo, podem produzir doenças ${ }^{31}$.

A apresentação clínica súbita à aguda cursa de morte súbita a sinais clínicos de apatia, hiporexia/anorexia, febre, tosse, secreção nasal mucopurulenta e dispneia/taquipneia, com curso de dois a cinco dias ${ }^{15,16,19,20}$. Embora a apresentação clínica e a gravidade da doença em adultos possam diferir dos jovens, a distribuição das lesões na necropsia é semelhante, refletindo os mecanismos comuns da doença. Lesões em qua-
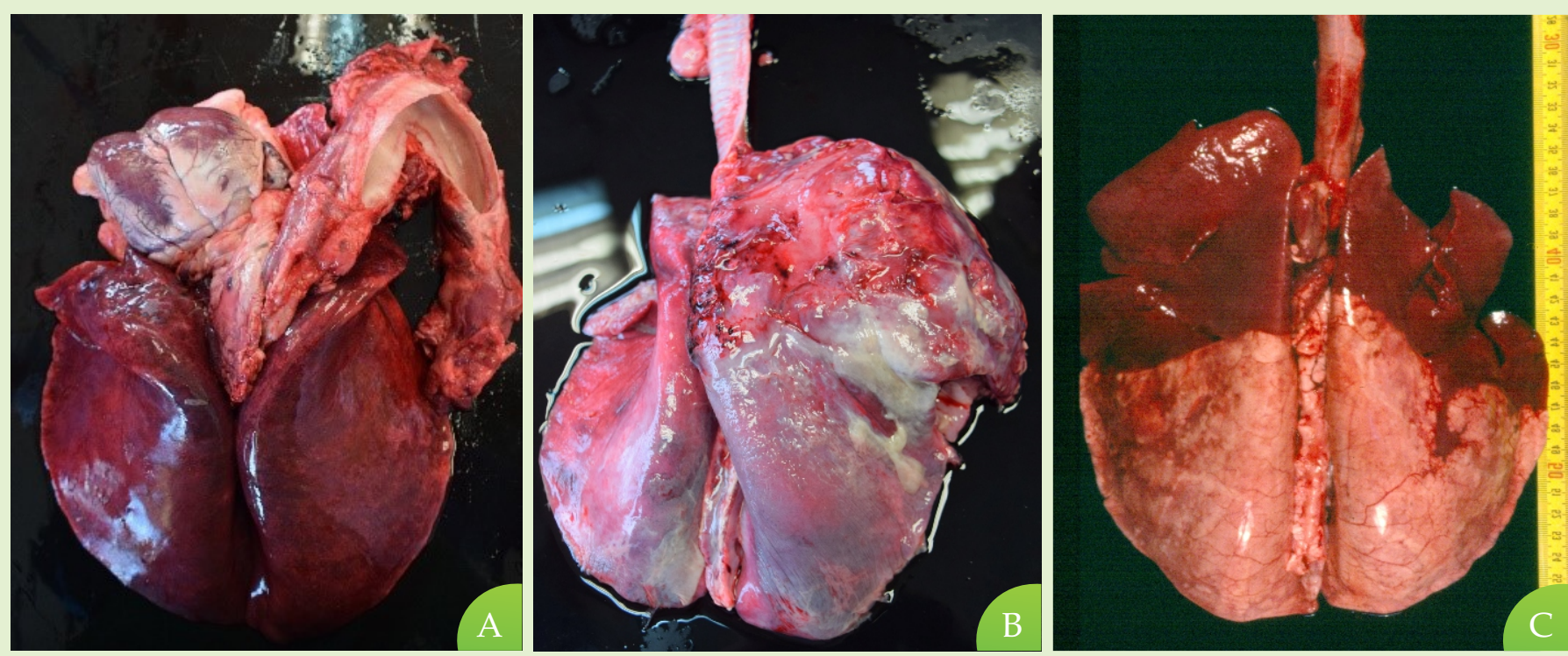

Figura 5. Caracterização macroscópica das afecções pulmonares pelo Complexo Respiratório Ovino (CRO). (A) Edema e hiperemia pulmonar difusa em quadro súbito (hiperagudo), (B) pleuropneumonia fibrinosa em quadro agudo e (C) pneumonia catarral em quadro crônico. 
dros súbitos (hiperagudos) são frequentemente caracterizadas por hemorragias, principalmente na cavidade nasal, pescoço, edema e hiperemia pulmonar (Figura 5A). As formas agudas são caracterizadas por diversos graus de consolidação pulmonar a partir dos exsudatos produzidos, incluindo pus causando pneumonia a broncopneumonia catarral, supurativa ou fibrinosa (Figura 5B). As pneumonias crônicas refletem o aparecimento de tecido fibroso, aumentando a gravidade da consolidação (Figura 5C).

A infecção pelo vírus da Língua Azul é um diagnóstico diferencial importante que também pode cursar com um quadro súbito de edema pulmonar e óbito por insuficiência respiratória, principalmente na espécie ovina (Figura 6A e B). Assim, outros achados de necropsia como edema facial e submandibular, petéquias, hiperemia e erosões na mucosa do trato gastrointestinal, derrame pleural, hidropericárdio, equimoses a hemorragias na camada média da artéria pulmonar (Figura 6C), epicárdio e endocárdio podem auxiliar a diferenciar casos de língua azul do CRO. Todavia, já foram descritas petéquias a hemorragias na base da artéria pulmonar e epicárdio em quadros septicêmicos pelo CRO. Assim, deve-se estar atento às diferenças epidemiológicas e sinais clínicos entre estes distúrbi$\mathrm{os}^{32}$.

$\mathrm{O}$ tratamento do $\mathrm{CRO}$ pode ser complicado pela variedade de patógenos, incluindo muitos sorotipos bacterianos envolvidos. As fluoroquinolonas, tilmicosina, tulatromicina, clortetraciclina, doxiciclina e oxitetraciclina têm sido eficazes contra $M$. haemolytica e Mycoplasma spp., que são os principais agentes do $\mathrm{CRO}$ nos animais jovens. A administração simultânea de antiinflamatórios não esteroidais (AINEs; ex.: flunixin meglumine $[2,2 \mathrm{mg} / \mathrm{kg}]$ ou meloxicam $[1,0$ $\mathrm{mg} / \mathrm{kg}$ ] SID) também é recomendada, principalmente em casos súbitos (edema pulmonar intenso) a agudos. Ainda, todos os animais com sinais clínicos devem ser submetidos ao esquema de tratamento completo a fim de se minimizar o risco de resistência bacteriana ${ }^{33}$.

Já o tratamento dos casos crônicos, na experiência dos autores, é menos aconselhável, devido ao grau de extensão da lesão pulmonar, formação de abscessos e ainda da necessidade de tratamentos longos para obter um grau adequado de remissão clínica e maior sobrevida do paciente. Todavia, já foi relatado, com sucesso, o tratamento diário com penicilina procaína por trinta dias em seis ovelhas com abscessos pulmonares pleurais/superficiais entre 2 a $8 \mathrm{~cm}$ de diâmetro diagnosticado pelo ultrassom ${ }^{34}$.

Em um surto de mannheimiose ovina, no teste in vitro de sensibilidade aos antimicrobianos, o isolado foi sensível à penicilina, ampicilina, azitromicina, enrofloxacina, eritromicina, estreptomicina, florfenicol,
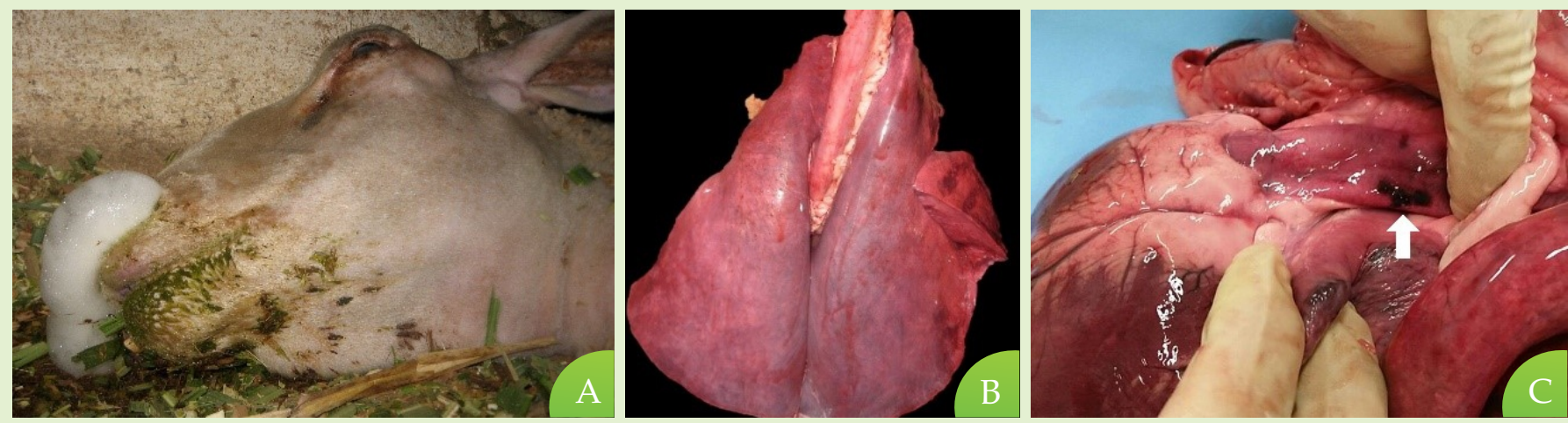

Figura 6. Óbito em ovino devido à infecção pelo vírus da Língua Azul. (A) Edema facial e submandibular associado à espuma saindo pelas narinas, (B) edema e hiperemia pulmonar e (C) lesões coalescentes hemorrágicas sobre a artéria pulmonar (seta). 
gentamicina, sulfazotrin e tetraciclina. A morbidade da doença foi de $25 \%$ neste rebanho e os casos clínicos foram tratados com oxitetraciclina (20 mg/kg; IM) e apresentaram recuperação após o tratamento ${ }^{16}$. Em um surto de mannheimiose caprina, foi relatada a eficácia do tratamento com benzilpenicilina procaína (40.000 $\mathrm{UI} / \mathrm{kg}$; dose de ataque) e diidroestreptomicina (15 $\mathrm{mg} / \mathrm{kg} ; \mathrm{SID})$ associado à flunixin meglumine $(2,2$ $\mathrm{mg} / \mathrm{kg}$; SID) por três dias consecutivos ${ }^{20}$. Ainda, segundo estes autores, o uso do antiinflamatório associado à detecção precoce do quadro clínico foram primordiais na recuperação do paciente.

A prevenção é essencial para o controle da doença e é baseada principalmente no adequado manejo zootécnico dos animais e instalações para evitar, ou pelo menos minimizar, os fatores de risco que causam estresse, melhorando o bem-estar animal e evitando agentes oportunistas. Por fim, embora ainda não tenham vacinas licenciadas contra enfermidades respiratórias para pequenos ruminantes no país, a exportação destes produtos (ex.: Providean Clostridial 10P') ou a produção de vacinas nacionais seria importante para auxiliar nos programas de controle, principalmente em rebanhos que apresentam surtos clínicos ou alta incidência de $\mathrm{CRO}^{35}$.

\section{- Adenocarcinoma Pulmonar Ovino (APO)}

O APO é um câncer de pulmão, contagioso, causado pelo retrovírus ovino jaagsiekte (JSRV) que induz a transformação de células epiteliais secretoras do trato respiratório distal. A doença já foi registrada nos principais países produtores de ovinos, com exceção da Austrália e da Nova Zelândia ${ }^{36}$. Existem poucos relatos da doença com confirmação viral na América Latina $^{37,38}$. No Brasil, há apenas um caso diagnosticado em ovino com descrição histopatológica ${ }^{39}$ e outros três casos (dois ovinos e um caprino) sem envolvimento viral confirmado por técnicas moleculares e imunohis- toquímicas $^{40}$.

Ovinos com APO apresentam sinais de doença respiratória afebril associada à perda de peso crônica. Não há manifestações clínicas quando a neoplasia é pequena, mas à medida que a doença progride, os sinais clínicos surgem. Inicialmente, os animais afetados apresentam-se menos ativos e, posteriormente, são detectados dispneia e ruídos adventícios como creptações e roncos causados pelo acúmulo de líquido e muco nas vias aéreas ${ }^{41}$. Nos estágios finais da doença, quantidades variáveis de fluido pulmonar seromucoso espumoso, de 10 até $400 \mathrm{~mL}$, são expelidos pelas narinas quando a cabeça do animal é abaixada ou os membros posteriores elevados (teste do "carrinho de mão") (Figura 7), sendo considerado um sinal característico de $\mathrm{APO}^{41-43}$. Os animais permanecem afebris e têm bom apetite, mas tornam-se caquéticos, e a morte ocorre inevitavelmente alguns meses após os sinais clínicos serem observados. No entanto, esse período é encurtado no caso de infecções bacterianas secundárias e a febre se torna um sinal evidente ${ }^{41}$.

Duas formas patológicas de APO são reconhecidas, a clássica e a atípica ${ }^{41}$. Nas formas clássicas, os pulmões parecem consideravelmente aumentados e não entram em colapso quando o tórax é aberto. As lesões neoplásicas ocorrem principalmente nas partes crânio-ventrais dos pulmões, embora qualquer parte possa estar envolvida. São difusos ou nodulares, de cor cinza ou roxa e apresentam consistência aumentada. As áreas neoplásicas variam desde pequenos nódulos discretos nos estágios iniciais até lesões extensas difusas, que frequentemente são delimitadas por pequenos nódulos satélites (Figura 8A). A superfície de corte da lesão tumoral tem uma aparência granular, úmida e frequentemente exsuda um líquido espumoso. Já as formas atípicas tendem a ser mais nodulares. Os nódulos podem ser solitários ou múltiplos e aparecem principalmente nos lobos caudais. São de cor branca perolada e consistência dura (Figura 8B). Quando seccionados, ficam muito bem demarcados das áreas circunvizi- 
nhas e sua superfície é seca. As formas atípicas geralmente são assintomáticas e aparecem como um achado incidental na necropsia ou estudos em matadouros. É importante ratificar que o APO atípico e clássico podem coexistir em um rebanho e em indivíduos. Por fim, devem-se diferenciar lesões macroscópicas de APO da broncopneumonia catarral supurativa ocasionada pelo CRO que podem ser similares. Basicamente, deve-se atentar a idade do animal (cordeiros e adultos com CRO e APO, respectivamente) e a consistência do tecido sob pressão que cede na broncopneumonia e não cede na $\mathrm{APO}{ }^{41,42}$. A via respiratória tem sido aceita como o modo de transmissão viral mais importante, mas o colostro e o leite também podem transmitir o vírus aos cordeiros ${ }^{44}$. Em rebanhos afetados com APO, em condições endêmicas, os ovinos infectados podem estar presentes em uma alta proporção, mas muito poucos desenvolvem sinais clínicos. Esses animais, aparentemente saudáveis, são responsáveis pela disseminação da doença porque é difícil identificar animais infectados ou em estágios pré-clínicos.

Não há testes de diagnóstico sorológico devido à falta de uma resposta imune detectável em animais infectados e, embora os testes moleculares do sangue estejam disponíveis, sua sensibilidade ainda é baixa. A

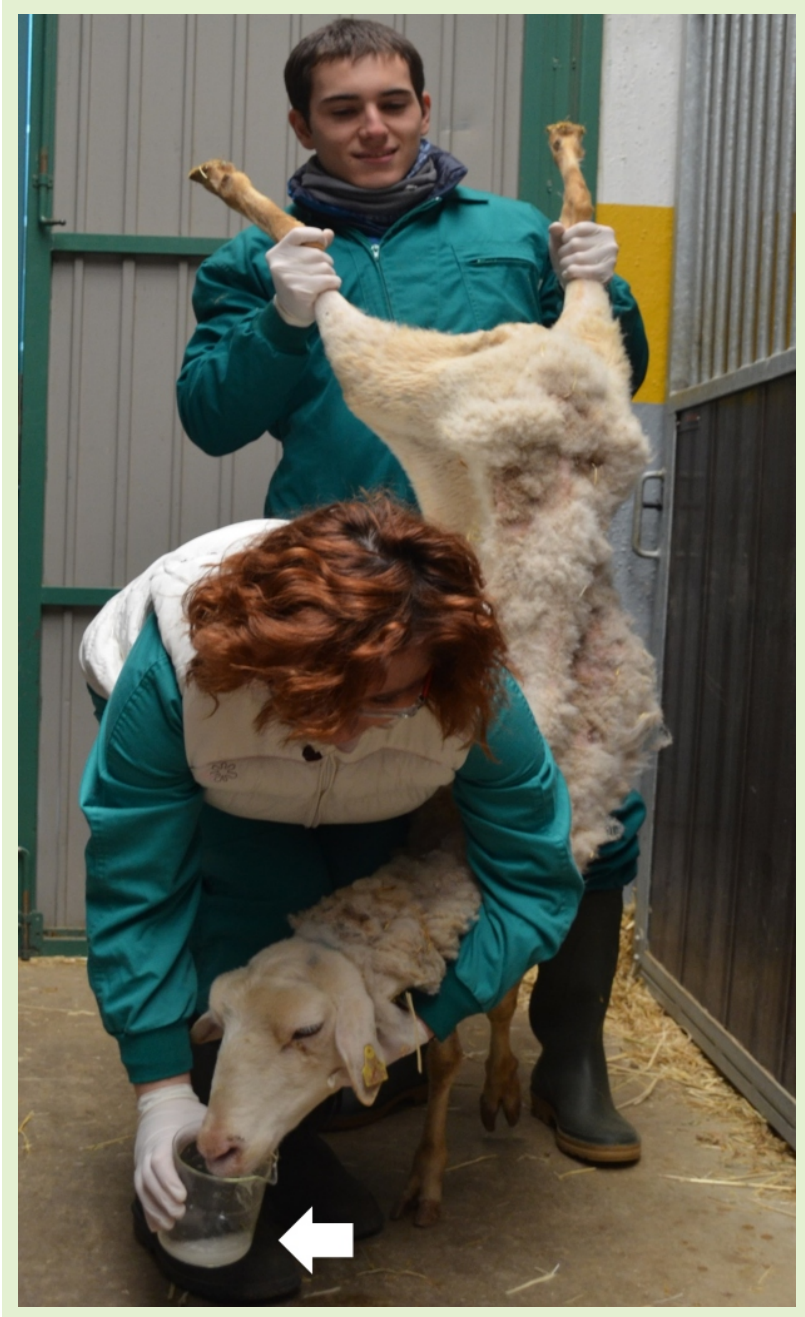

Figura 7. Teste de "carrinho de mão" realizado em ovelha com APO. Resultado positivo com presença de fluido pulmonar seromucoso espumoso sendo expelido pelas narinas (seta).
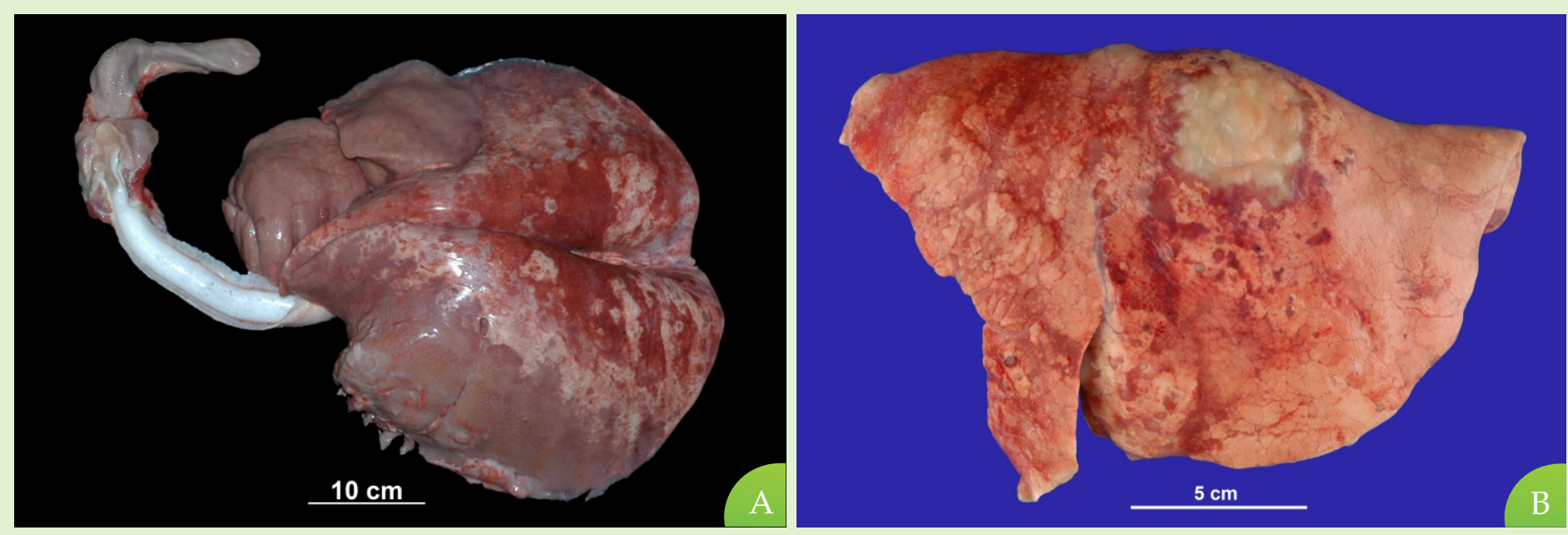

Figura 8. Caracterização macroscópica do adenocarcinoma pulmonar ovino (APO) na espécie ovina. (A) Achado macroscópico de APO clássico com lesões ventrais bem demarcadas de coloração acinzentada e consistência firme e (B) achado macroscópico de APO atípico com lesão focal circunscrita de $4 \mathrm{~cm}$ acinzentada a amarelada no lobo caudal. 
ultrassonografia torácica é outro método que tem sido investigado para a detecção de lesões de APO in vivo e proposto para sua erradicação em rebanhos afetados ${ }^{45}$. No entanto, essa metodologia não cobre em totalidade o campo pulmonar e não garante a detecção de tumores menores que $2 \mathrm{~cm}$. Por estes motivos, a doença não é bem controlada, até o momento, e continua a causar perdas econômicas.

As estratégias de controle baseadas no colostro e no manejo do leite demonstraram ser eficazes, mas onerosas para a maioria dos lotes comerciais ${ }^{44}$. Nos últimos anos, os esforços para o controle da doença têm se concentrado na busca de métodos de diagnóstico precoce, e no futuro parece ser o estabelecimento de um status de baixo risco para o APO nos rebanhos. No entanto, melhorar a identificação de animais infectados é essencial para a implementação de estratégias eficientes para a erradicação do $\mathrm{APO}^{36}$.

\section{- Pneumonia por aspiração}

A pneumonia por aspiração é uma infecção pulmonar comumente causada pela inalação de materiais estranhos, produzindo inflamação e necrose do parênquima pulmonar. Às vezes, é descrita como pneumonia por corpo estranho, pneumonia por inalação ou pneumonia gangrenosa e foi diagnosticada em vários animais domésticos ${ }^{46-49}$. O material aspirado é geralmente direcionado aos lobos ântero-ventrais do pulmão, onde produz uma broncopneumonia necrosante moderada a grave (Figura 9A e B), hiperaguda ou subaguda, dependendo da composição do material inalado, dos microrganismos envolvidos e das respostas do hospedeiro $^{50}$.

A aspiração de material estranho no sistema respiratório pode ser do conteúdo ruminal após episódios de timpanismo ou durante a intubação e anestesia
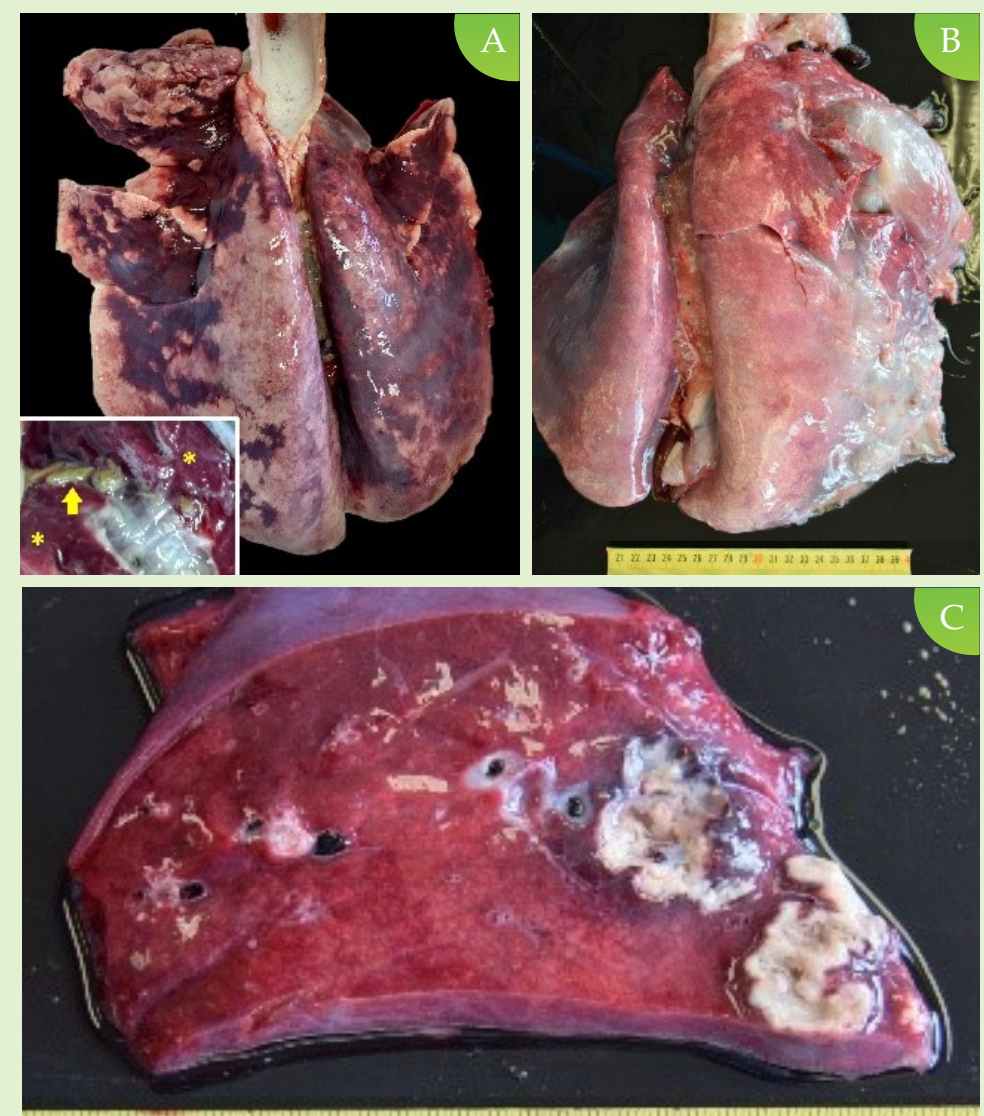

$\begin{array}{lllllllllllll}4 & 25 & 26 & 27 & 28 & 29 & 30 & 31 & 32 & 33 & 34 & 35 & 36\end{array}$

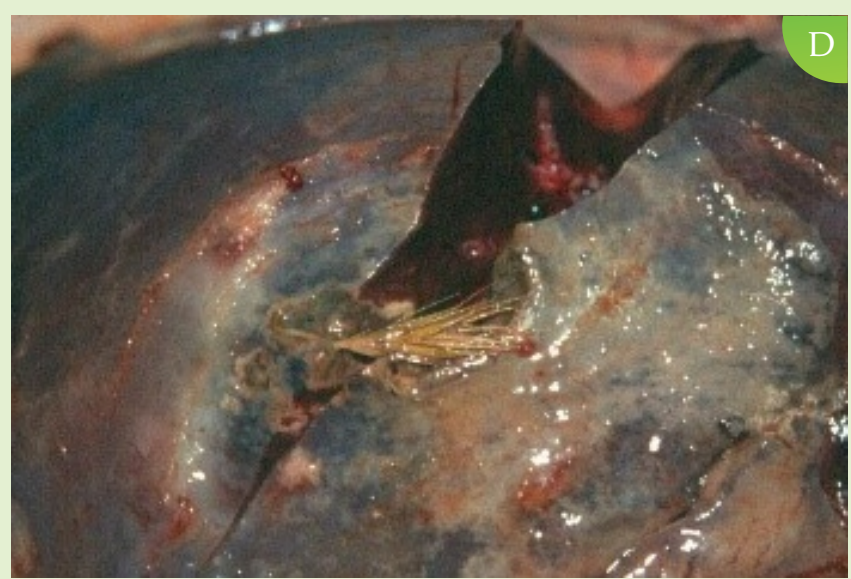

Figura 9. Caracterização macroscópica da pneumonia por aspiração (gangrenosa) na espécie ovina. (A) Quadro agudo; pulmão (histórico de broncoaspiração durante intubação cirúrgica) contendo áreas de atelectasia (asterisco) e consolidação difusa devido ao conteúdo aspirado (seta), além de espuma nas vias aéreas. (B) quadro crônico; pulmão de ovino com lesões multifocais de necrose e acúmulo de exsudato purulento de odor pútrido associado a pleurite, $(\mathrm{C})$ corte do lobo pulmonar afetado e (D) pulmão com material vegetal causando pneumonia por aspiração no interior da lesão. 
geral $^{51}$. Além disso, a aspiração de medicações orais (ex.: antiparasitários) ou leite quando administrados inadequadamente, assim como do líquido contido em banhos de imersões contra ectoparasitos (prática em desuso) também podem ocorrer ${ }^{48}$. Da mesma forma, a hemiplegia laríngea ${ }^{52}$ ou mionecrose esofágica por infecção pelo vírus da Língua $\mathrm{Azul}^{53}$ podem evoluir para a pneumonia por aspiração. Além disso, distúrbios nas vias áreas que dificultam a respiração adequada favorecem a inalação de matéria vegetal e o surgimento dessas condições. Portanto, pode-se encontrar a pneumonia por aspiração associada a outros distúrbios respiratórios $^{50}$. O corpo estranho (e.g. material vegetal) é frequentemente visto no exame post mortem e em cortes histológicos de lesões pulmonares de animais com pneumonia por aspiração. A presença deste material vegetal pode sugerir que sementes ou espigas de cereais foram inaladas durante a alimentação desses animais (Figura 9D).

A maioria dos microrganismos produtores de pneumonia por aspiração são habitantes normais da nasofaringe ou do meio ambiente. Uma variedade de bactérias anaeróbias e aeróbias, fungos e vírus foram isolados dessas lesões gangrenosas, indicando que a maioria envolve infecções mistas ${ }^{52,54}$. Em levantamento realizado que envolveu 195 ovelhas de descarte, T. pyogenes, P. multocida e Mycoplasma ovipneumoniae foram os microrganismos mais frequentemente isolados neste tipo de lesão ${ }^{50}$.

Os sinais clínicos geralmente aparecem dentro de uma ou duas semanas após o processo aspirativo. Todavia, a associação do quadro com a intervenção que o originou nem sempre é possível. Os animais afetados se separam do lote, exibindo apatia, inapetência, posição antálgica e febre de até $41,5^{\circ} \mathrm{C}^{55}$. Os sinais clínicos respiratórios podem incluir tosse, dispneia, crepitações e, quando o processo progride suficientemente, pode ser detectado odor anormal do hálito próprios dos exsudatos necrosantes que ocorrem na pneumonia por aspiração ${ }^{51,55,56}$. Como o exame físico, isolado, nem sempre leva a um diagnóstico adequado, métodos auxiliares como ultrassonografia, raio-X, LTB e LBA se tornam ferramentas úteis ${ }^{25-27}$.

Se a terapia for possível, os resultados dos testes de sensibilidade aos antibióticos realizados em amostras de exsudato podem orientar a escolha do agente antimicrobiano a ser administrado. Da mesma forma, se for de conhecimento que um animal aspirou um corpo estranho há pouco tempo, o tratamento deve ser iniciado imediatamente, antes do surgimento do quadro respiratório. Portanto, nos casos iniciais, o tratamento pode ser realizado à base de antibióticos $\beta$ lactâmicos por pelo menos sete dias associados a AINEs nos primeiros dias do protocolo terapêutico para melhorar a performance respiratória ${ }^{48}$.

Apesar dos tratamentos e esforços para controlar a evolução da doença, o prognóstico é desfavorável (principalmente na fase crônica) e muitos animais morrem ou devem passar pela eutanásia por questões humanitárias. Assim, o empenho deve ser direcionado na prevenção, para que os fatores de risco para aspiração sejam reconhecidos, particularmente os riscos relacionados ao manejo inadequado dos animais ${ }^{50}$.

\section{- Pneumonias fúngicas}

Cryptococcus neoformans, Histoplasma capsulatum, Coccidioides immitis, Blastomyces dermatitidis, Pneumocystis jiroveci, Aspergillus spp., Candida spp. e outros fungos menos comuns, vêm sendo identificados como agentes causadores de pneumonia fúngica em hospedeiros imunocomprometidos ou não. A infecção é geralmente causada pela inalação de esporos, que podem levar à disseminação hemolinfática. Os tecidos e secreções pulmonares são um excelente ambiente para esses microorganismos resultando em uma pneumonia piogranulomatosa ativa de caráter agudo a crônico $^{87,88}$.

As doenças produzidas por Aspergillus spp. incluem gastroenterite, pneumonia, mastite e aborto 

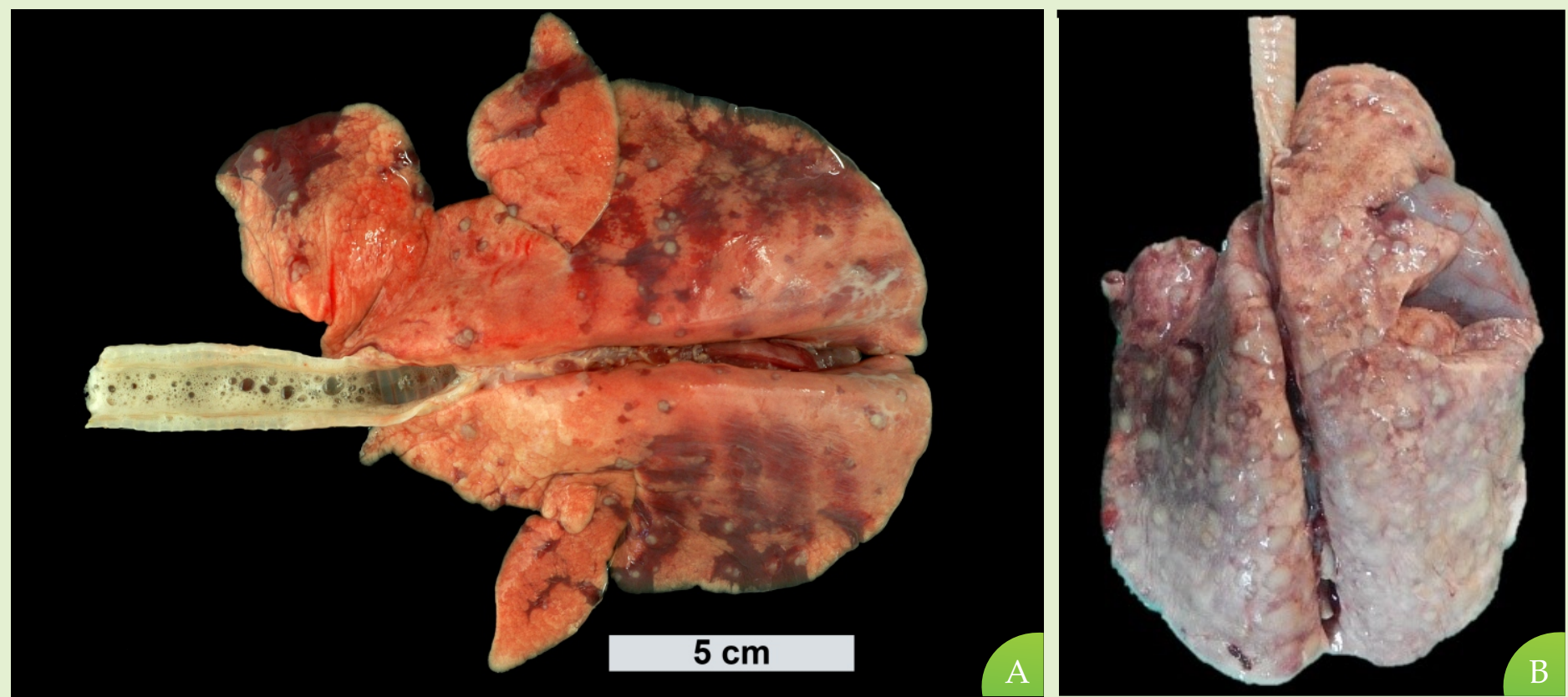

Figura 14. Caracterização macroscópica da pneumonia fúngica na espécie ovina. (A e B) Pulmões infectados por Aspergillus fumigatus contendo lesões salientes multifocais de aspecto caseoso, halo vermelho nas extremidades e firmes, ao corte.

em ruminantes ${ }^{89}$. A aspergilose pulmonar, principalmente por Aspergillus fumigatus, é ocasionalmente descrita em pequenos ruminantes, principalmente em animais jovens confinados ${ }^{87,90-95}$. O uso de antibioticoterapia prolongada, fatores estressantes, doenças crônicas concomitantes e ingestão de ração mofada estão implicados nesta doença ${ }^{94}$. Clinicamente, é caracterizada por apatia, anorexia, tosse, dispneia e secreção nasal ${ }^{87,90,95}$. Na necropsia, são constatadas lesões multifocais a coalescentes oriundas da inflamação granulomatosa a piogranulomatosa nos pulmões (Figura 14) ou ainda em outros órgãos como glândulas mamárias, linfonodos, rins, pulmão, fígado, coração, estômagos e cérebro ${ }^{96}$.

No diagnóstico in vivo, têm sido descritas técnicas de imagem como ultrassonografia e raio-X.Também pode ser realizada a punção aspirativa por agulha fina (PAAF) guiada por ultrassom ou LBA para caracterização da celularidade e/ou detecção do agente ${ }^{88}$. Testes sorológicos, PCR e colorações especiais também podem ser utilizados ${ }^{87}$. O diagnóstico post mortem é baseado em lesões macro e microscópicas. A confirmação, entretanto, depende da detecção do agente por métodos imunohistoquímicos, moleculares e/ou baseados em cultura associados à presença do agente nas lesões histológicas ${ }^{87}$.

Os medicamentos de escolha incluem; itraconazol, fluconazol e anfotericina B complexada com lipídios, além do uso de antiinflamatórios e oxigenioterapia nos casos graves ${ }^{88}$. A pneumonia fúngica, geralmente, ocorre de forma isolada, no entanto, em caso de surto, um estudo epidemiológico deve ser conduzido de modo a detectar os fatores de risco associados a esta enfermidade no plantel.

\section{TRANSTORNOS NÃO PRODUTIVOS}

\section{- Forma pulmonar das Lentiviroses de Pequenos Ruminantes (LVPR)}

As infecções por lentivirus em pequenos ruminantes estão disseminadas na maioria dos países do mundo $^{57}$. Durante décadas, os vírus responsáveis pelas infecções lentivirais em pequenos ruminantes foram 

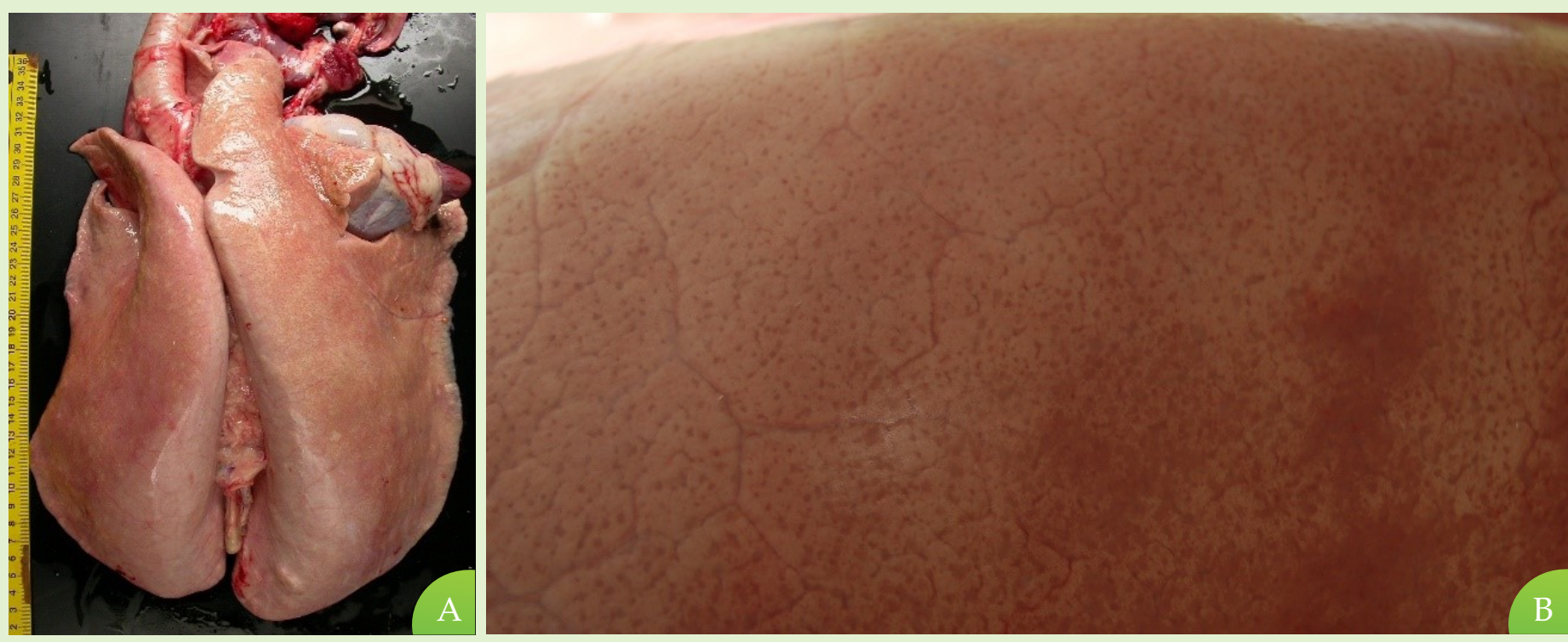

Figura 10. Macroscopia de pulmão ovino acometido por Lentiviroses de Pequenos Ruminantes (LVPR). (A) Forma pulmonar da lentivirose com pulmão aumentado e de coloração acinzentada difusa e (B) miríade de pontos cinza na superfície pleural.

nomeados como a doença causada pelo Vírus MaediVisna (MVV) em ovinos ou Vírus da Artrite Encefalite Caprina (CAEV) em caprinos. Atualmente, o vírus responsável pela infecção é considerado o mesmo, e a doença conhecida como LVPR ${ }^{58}$. A frequência de anticorpos contra a LVPR no Brasil tem variado de acordo com a região estudada entre $0 \%$ a $31,7 \%$ e $0,3 \%$ a $52,2 \%$ na espécie ovina e caprina, respectivamente. Embora as frequências entre as espécies possam ser similares, por questões epidemiológicas próprias, rebanhos de caprinos leiteiros são os principais afetados no país ${ }^{59}$.

As lentiviroses apresentam quatro formas clínicas principais: respiratória (pneumonia intersticial), nervosa (leucoencefalomielite), mastítica (mastite intersticial) e articular (artrite proliferativa) ${ }^{57}$. Embora essas quatro formas clínicas possam estar presentes simultaneamente no animal, o quadro clínico na espécie caprina é representado, principalmente, pela poliartrite, mastite endurativa e emagrecimento progressi$\mathrm{vo}^{59,60}$.Já a forma clínica respiratória é a mais prevalente na espécie ovina e geralmente é observada em animais adultos ( $\geq 2$ anos de idade). Os animais apresentam dispneia e taquipneia, fraqueza, perda de peso e demo- ra no acompanhamento do rebanho. Se o caso não for complicado, não é observada tosse, secreção nasal ou febre. Além disso, várias doenças concomitantes, como $\mathrm{APO}, \mathrm{CRO}$ ou pneumonia por aspiração, podem estar presentes, complicando o diagnóstico clínico da doença $^{58}$. No exame post mortem, os pulmões apresentam aumento de tamanho, volume e peso e uma descoloração acinzentada difusa com uma miríade de pontos cinza na superfície pleural (Figura 10). Os linfonodos mediastinais também aumentam de tamanho, ultrapassando o limite dos lobos caudais ${ }^{58}$.

$\mathrm{O}$ controle das lentiviroses pode ser alcançado pela combinação de testes sorológicos e moleculares periódicos e no manejo do rebanho ${ }^{11}$. No entanto, limitações do diagnóstico sorológico ou falhas recorrentes no manejo tornam a erradicação da infecção uma meta difícil para a grande maioria dos rebanhos ${ }^{58}$. O método específico a ser aplicado em determinado rebanho para o controle da LVPR dependerá da soroprevalência e da disponibilidade de recursos e materiais ${ }^{57}$. Por fim, um exemplo de sucesso na erradicação de LVPR em caprinos leiteiros foi descrito no Japão, por meio de três estratégias: a remoção dos cabritos imediatamente após o nascimento, isolamento de cada geração, e des- 
carte periódico dos positivos em testes sorológicos e/ou moleculares (IDGA e PCR). Após quatro gerações, houve a conversão de rebanhos infectados para livres de LVPR e aumento na produção leiteira ${ }^{61}$.

\section{- Forma pulmonar da Linfadenite Caseosa (LC)}

A linfadenite caseosa é causada por Corynebacterium pseudotuberculosis e possui tanto a forma superficial caracterizada pelo desenvolvimento de abscessos em linfonodos superficiais quanto a forma visceral afetando linfonodos e órgãos internos ${ }^{62}$. A LC está distribuída em todo o mundo, causando importantes perdas econômicas $^{62,63}$.

Um estudo espanhol com ovinos mantidos em regime semi-intensivo a intensivo, avaliou 498 ovelhas de descarte que foram examinadas e eutanasiadas, com objetivo de se obter o diagnóstico final da causa do descarte. Dos animais estudados, 29,5\% (147/498) apresentaram lesões compatíveis com LC que foram posteriormente confirmadas pelo isolamento de $C$. pseudotuberculosis. Ainda, 72,8 \% (107/147) apresentaram a forma visceral enquanto apenas 21,8\% (32/147) apresentaram a forma superficial. $\mathrm{Na}$ forma visceral da doença, 85,1\% (91/107) dos afetados apresentavam lesões no sistema respiratório ${ }^{64}$. Deste modo, considerando a alta taxa de lesões de LC na cavidade torácica, incluindo linfonodo mediastinal e/ou parênquima pulmonar (Figura 11) produzindo sinais clínicos respiratórios, justifica-se a inclusão da LC no diagnóstico diferencial de distúrbios respiratórios. Todavia, a apresentação clínica da LC no Brasil pode ser distinta, pois a forma superficial da doença é a principal relatada em abatedouros no país com raras descrições da forma visceral pulmonar ${ }^{65-67}$.

Os sinais clínicos respiratórios associados a LC geralmente não são reconhecidos prontamente. Principalmente se apenas a dispneia for detectada sem sons audíveis da cavidade torácica, como ocorre quando o conteúdo dos abscessos é encapsulado. Deste modo, técnicas de diagnóstico por imagem auxiliam na confirmação da forma visceral da doença, assim como o histórico de emagrecimento progressivo e perda no desempenho produtivo do animal.

Embora o contato direto seja descrito como a principal via de transmissão, a via respiratória por animais infectados com lesões pulmonares é a principal
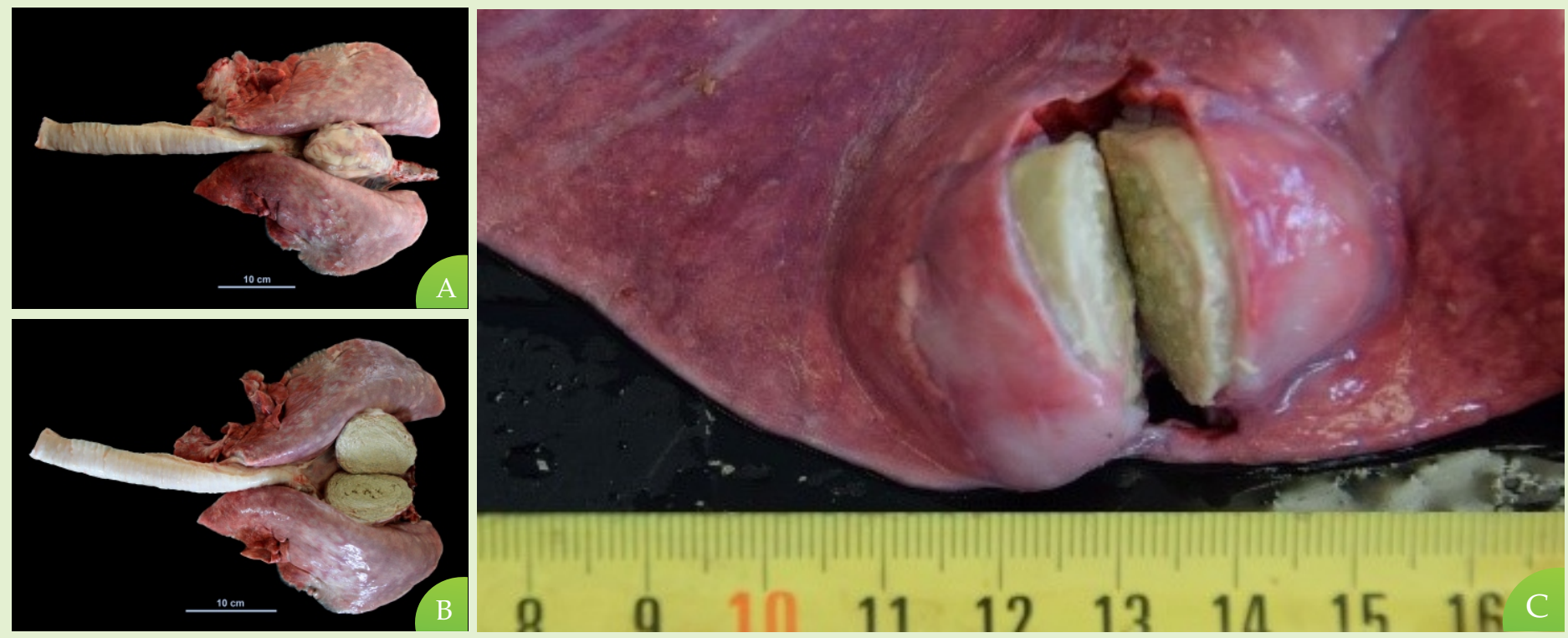

Figura 11. Caracterização macroscópica da forma visceral pulmonar da linfadenite caseosa (LC) na espécie ovina. (A) Pulmão com linfonodo mediastinal acometido por LC, (B) linfonodo seccionado e (C) piogranuloma de LC dentro do parênquima pulmonar. 
fonte de exposição a animais não infectados no rebanho ${ }^{62,68}$.

A melhor estratégia para controlar a LC é o protocolo vacinal para os animais saudáveis e de reposição no rebanho, juntamente com o descarte contínuo dos infectados ${ }^{68}$. Como acontecem com muitos programas de vacinação, as vacinas licenciadas suprimem a doença em vez de conferir proteção completa aos animais imunizados, então o LC poderá persistir por um tempo na propriedade apesar das vacinações periódi$\operatorname{cas}^{63,69}$. No entanto, os esquemas de vacinação devem ser implementados para reduzir o número de animais com quadro clínico e possíveis fontes de disseminação para o rebanho. Ainda, deve-se evitar o rompimento espontâneo de abscessos superficiais, pois estes são uma intensa fonte de contaminação ambiental. Assim, animais com a forma clínica superficial, devem ser separados do lote sendo destinados para o descarte ou drenagem apropriada dos abcessos até completa cicatrização da lesão.

\section{- Forma pulmonar das Micoplasmoses}

As principais doenças respiratórias causadas pelo gênero Mycoplasma são a pleuropneumonia caprina contagiosa (principalmente em caprinos), agalactia contagiosa (ovinos e caprinos) e pneumonia atípica (geralmente ovinos). Em respeito à variação antigênica, os micoplasmas possuem mecanismos complexos que os permitem evadir o sistema imunológico. Portanto, podem causar diversos sinais clínicos com relevante impacto econômico na produção de pequenos ruminantes e surtos em populações selvagens atingindo alta morbidade (até 100\%) e mortalidade variá$\operatorname{vel}(10 \text { a } 100 \%)^{70-72}$.

Existem muitas espécies associadas a condições pneumônicas em pequenos ruminantes, a saber, Mycoplasma mycoides subsp. mycoides, $M$. mycoides subsp. capri, $M$. capricolum subsp. capripneumoniae, M. capricolum subsp. capricolum, $M$. agalactiae, $M$. ovipneumo- niae e $M$. arginini. As síndromes associadas à infecção por Mycoplasma spp. variam de quadros agudos (septicemia e morte) a crônicos que resultam em queda na produção. Além dos processos respiratórios, quadros de artrite, mastite, vesiculite seminal, ampulite, epididimite, orquite, uretrite, conjuntivite e meningite também podem ser constatados ${ }^{70,71}$. Assim, a maioria dos micoplasmas produzem um conglomerado de sinais clínicos (síndrome) que dificultam o diagnóstico. Ainda, a infecção congênita por $M$. agalactiae, em especial, pode resultar no nascimento de crias com poliartrite e imunotolerantes ${ }^{73,74}$.

Outro desafio apresentado pelo gênero Mycoplasma está na dificuldade de isolamento devido à falta de locais especializados, procedimentos dispendiosos e também à meticulosidade do patógeno. A LVPR é considerada o principal diagnóstico diferencial das micoplasmoses devido a apresentação clínica similar. Todavia, não têm sido encontradas correlações e fatores de riscos entre tais doenças em rebanhos caprinos no Nordeste brasileiro ${ }^{75}$.

Em estudo com carcaças de pequenos ruminantes submetidas para fins diagnósticos, verificaram microrganismos patogênicos em 32,4\% (123/380) das lesões pulmonares. Infecções por Mycoplasma spp. foram demonstradas em cerca de $2 / 3$ dos casos positivos. Em 44,7\% (55/123) destes, apenas micoplasmas, de espécies diferentes, isoladamente ou combinadas, foram detectados. Em 20,3\% (25/123) dos casos, coinfecções por Mycoplasma spp. e outros patógenos (por exemplo, $M$. haemolytica e $P$. multocida) foram demonstradas, enquanto que em 35\% (43/123) dos casos não foram verificadas a infecção por Mycoplasma spp. ${ }^{76}$.

No semiárido pernambucano, verificou-se que caprinos e ovinos de rebanhos de corte, mantidos em sistema extensivo em que não é adotada a quarentena e limpeza das instalações, apresentam maiores chances da presença do $M$. agalactiae e $M$. mycoides cluster ${ }^{77}$. Igualmente, a maioria das espécies de micoplasmas vem sendo isoladas em determinadas épocas do ano, 

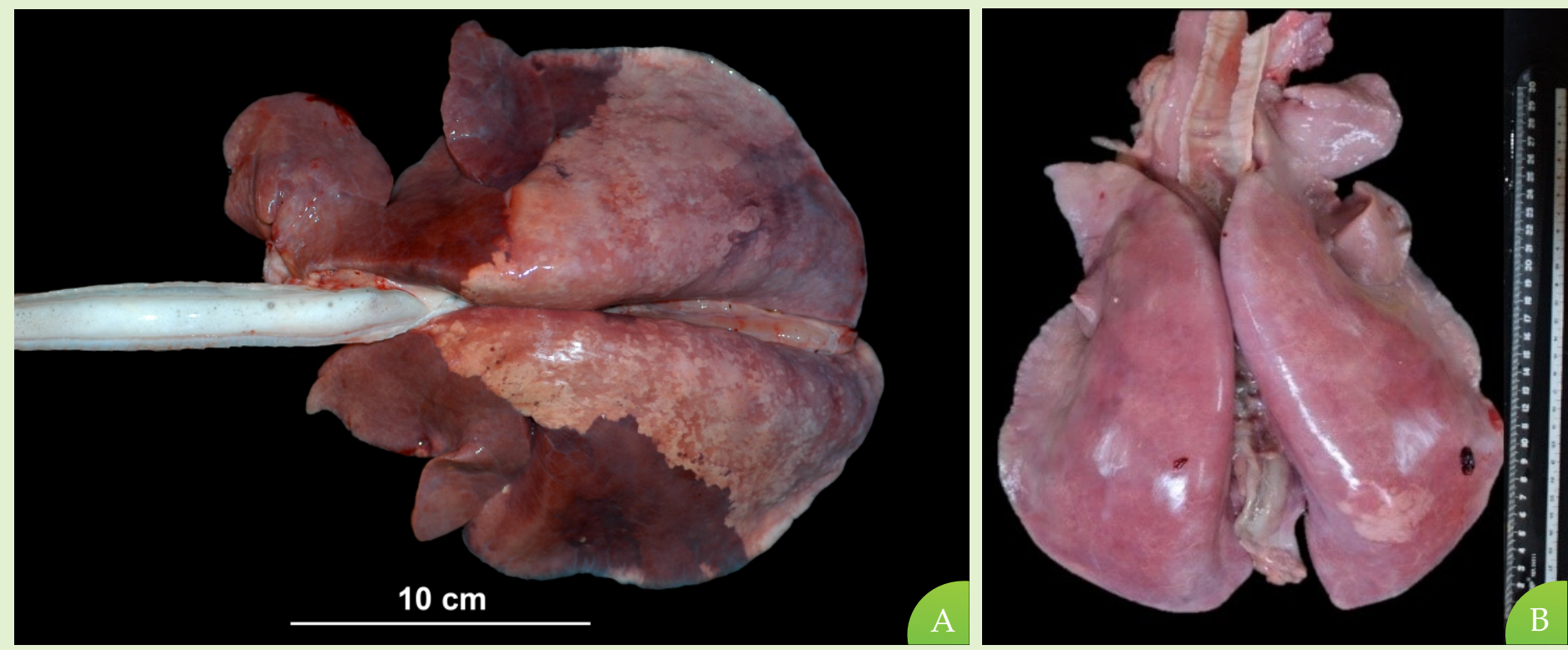

Figura 12. Caracterização macroscópica das pneumonias por micoplasmoses na espécie ovina. (A) Quadro misto associado à família Pasteurellaceae gerando pneumonia catarral produtiva com espumas nas vias aéreas e lobos crânio-ventrais consolidados, deprimidos e castanho-avermelhados e (B) quadro com pneumonia intersticial crônica e consolidação multilobar cranioventral acinzentada bilateral.

indicando um perfil sazonal e que temperaturas mais altas e menor umidade relativa favorecem a presença destes agentes ${ }^{78}$.

M. ovipneumoniae e, principalmente, $M$. arginini têm sido associados a pneumonia em ovinos ${ }^{76,78,79} \mathrm{e}$ em carneiros selvagens por predispor à morte por pneumonia pela $M$. haemolytica ${ }^{80}$. Assim, existem dois padrões principais de achados necroscópicos. Quando associado ao CRO e a família Pasteurellaceae, destacase uma pneumonia catarral, normalmente produtiva e aguda (Figura 13A), com lobos crânio-ventrais consolidados, deprimidos, castanho-avermelhados e a pleurite também pode estar presente. Já em quadros independentes, produz uma pneumonia intersticial crônica com consolidação pulmonar irregular e padrão lobar a difuso nos lobos cranioventral a caudal dos pulmões afetados (Figura 13B). Na histopatologia, é verificada uma pneumonia broncointersticial a broncopneumonia purulenta a fibrinopurulenta ${ }^{79}$.

Diversos antibióticos vêm sendo testados na terapêutica da micoplasmose em ovinos e caprinos. Eles incluem oxitetraciclina, enrofloxacina, tilosina, florfenicol, tiamulina e danofloxacina ${ }^{71}$.

Os métodos convencionais para o diagnóstico de micoplasmose incluem o isolamento, seguido por caracterização bioquímica e coloração. Ainda, testes sorológicos como inibição de crescimento, imunodifusão em gel de ágar, eletroforese em contracorrente, fixação de complemento, PAGE e outros podem ser utilizados. No entanto, a reatividade cruzada de espécies estreitamente relacionadas não pode ser diferenciada pelos testes sorológicos ${ }^{70}$. Assim, estudos mais recentes vêm indicando o uso do diagnóstico molecular das micoplasmoses pela maior sensibilidade frente aos resultados obtidos na cultura ${ }^{79}$.

Medidas profiláticas são as melhores opções para prevenção e controle, embora faltem vacinas específicas na maioria dos países. No futuro, para a prevenção e controle da doença, o principal objetivo deve ser o desenvolvimento de redes de diagnóstico sensíveis e específicas para a detecção precoce das micoplasmoses no rebanho ou indivíduos, assim como na viabilização de vacinas e de cepas específicas locais para controle da enfermidade ${ }^{71}$. 


\section{- Pneumonias Parasitárias}

Os principais parasitos pulmonares de pequenos ruminantes são Dictyocaulus filaria, Protostrongylus rufescens e Muellerius capillaris. D. filaria pertence à superfamília Trichostrongyloidea, enquanto os dois últimos pertencem à Metastrongyloidea, que têm ciclos de vida diretos e indiretos, respectivamente ${ }^{81}$. Os caprinos são mais suscetíveis à infecção que os ovinos. Normalmente, as infecções são assintomáticas, mas dependendo da gravidade, idade e estado imunológico do animal, os sinais clínicos variam de tosse intermitente e taquipneia até tosse persistente com dificuldade a insuficiência respiratória ${ }^{81-83}$.

Dentre os achados de necropsia, os brônquios na infecção por $D$. filaria (especialmente os dos lobos caudais) contêm massas emaranhadas de helmintos misturados com exsudatos espumosos e lóbulos atelectáticos posteriores aos brônquios infectados (Figuras $13 \mathrm{Ae} \mathrm{B})^{81-83}$.

Bronquíolos infectados com P. rufescens geralmente são obliterados devido aos helmintos e possuem exsudatos, consequentemente, os lóbulos afetados podem estar atelectásicos. Pulmões infectados $\operatorname{com} M$. capillaris contém lóbulos vermelhos a acinzentados com 1 a 2 mm de diâmetro. Essas lesões, localizadas no espaço subpleural dos lobos caudais, variam em consistência, número e forma (Figura 13C). Ainda, a infecção por M. capillaris em caprinos leva a uma apresentação difusa bastante diferente da reação nodular e pneumonia intersticial nos ovinos ${ }^{81-83}$.

O diagnóstico da doença é feito pelo exame coproparasitológico por meio do método de Baermann ou FLOTAC modificado para detectar as larvas $\mathrm{L1}^{84} \mathrm{e}$ exame post mortem dos pulmões para identificação macro ou microscópica dos parasitos ${ }^{81-83}$. Na espécie bovina, um método rápido e pouco dispendioso para avaliar a exposição do rebanho a dictiocaulose é o teste ELISA a partir de amostras do tanque de leite. Assim,é uma ferramenta útil dentro de um programa de monitoramento da saúde em rebanhos leiteiros ${ }^{85}$.

O tratamento requer o uso de anti-helmínticos eficazes contra tais agentes como benzimidazóis, imidazotiazóis e lactonas macrocíclicas. A prevenção e o controle podem ser alcançados de forma mais eficaz pela integração de três abordagens inter-relacionadas: administração de medicamentos anti-helmínticos eficazes, imunização em países onde vacinas são comercializadas e práticas de gestão visando romper o ciclo epidemiológico da doençç ${ }^{81-83,86}$.
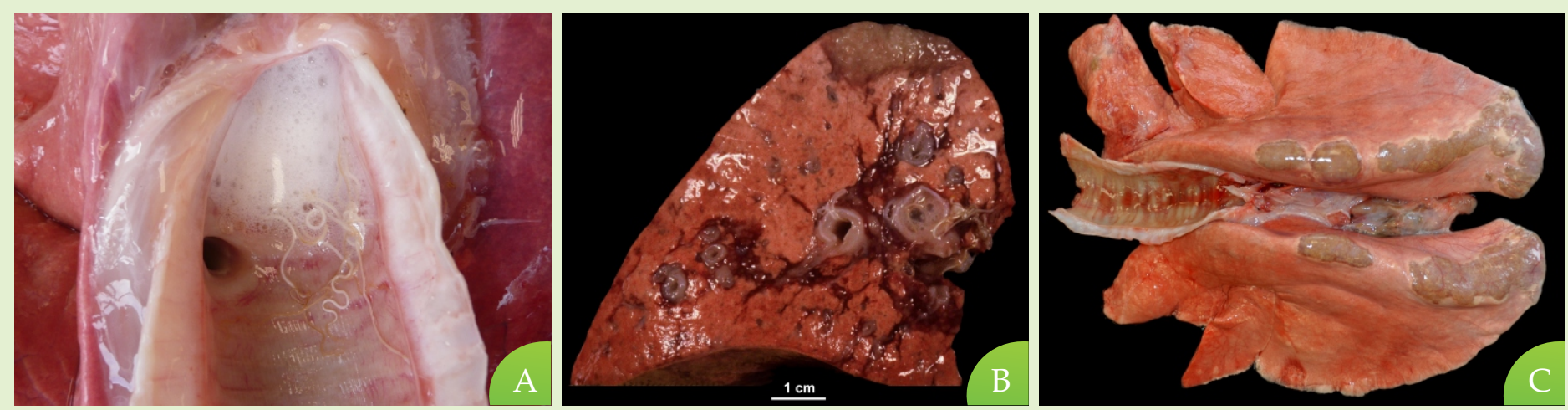

Figura 13. Caracterização macroscópica da pneumonia parasitária na espécie ovina. (A) Região próxima a bifurcação da traqueia contendo helmintos (D. filaria) misturados a misturados a exsudato espumoso, (B) corte transversal de lobo pulmonar contendo $D$. filaria em vias aéreas com atelectasia adjacente. Dorsalmente, há uma área de consolidação acinzentada focal por M. capillaris e (C) pulmão infectado por $M$. capillaris contendo lesões acinzentadas multifocais a coalescentes na superfície dos lobos caudais. 
Quadro 1. Relação de livros e artigos que abordam distúrbios do trato respiratório inferior junto a metodologias diagnósticas em pequenos ruminantes.

\section{LITERATURA ADICIONAL}

\section{Anamnese, avaliação das instalações, exame clínico e exames complementares}

ANTÓN, J.J.R.; MAYAYO, L.M.F. Exploración del aparato respiratório. In: ANTÓN, J.J.R.; MAYAYO, L.M.F. La exploración clínica del ganado ovino y su entorno. Zaragoza: Servet, p.115-147, 2007.

\section{Avaliação ultrassonográfica do tórax}

SCOTT, P.R. Practical Use of ultrasound scan in small ruminant medicine and surgery. Veterinary Clinics of North America: Food Animal Practice, v.32, n.1, p.181-205, 2016.

SCOTT, P.R. Thoracic ultrasonography as an adjunct to clinical examination in sheep. Small Ruminant Research, v.152, p.107$118,2017$.

CASTELLS, E. et al. Diagnostic imaging techniques of the respiratory tract of sheep. Small Ruminant Research, v.180, p.112$126,2019$.

\section{Lavado traqueobrônquico e broncoalveolar}

MARCONDES, J.S.; GONÇALVES, R.C. Metodologia de colheita de células do trato respiratório em ovinos sadios através da técnica de lavagem traqueobrônquica por via nasotraqueal. Ciência Animal Brasileira, v.9, n.2, p.418-426, 2008.

MARCONDES, J.S. et al. Lavado traqueobrônquico por via nasotraqueal como metodologia de colheita de células do trato respiratório de ovinos sadios e portadores de afecções pulmonares. Pesquisa Veterinária Brasileira, v.31, n.4, p.281-286, 2011.

JARIKRE, A.T. et al. Bronchoalveolar lavage fluid cellular and haematological changes in different types of caprine pneumonia. Nigerian Journal of Physiological Sciences, v.31, n.1, p.31-36, 2016.

\section{Patologia}

FERRER, L.M. et al. Atlas de patología ovina. Zaragoza: Servet, 2002, 312p.

\section{CONSIDERAÇÕES FINAIS}

As doenças do trato respiratório inferior em pequenos ruminantes possuem uma apresentação clínica genérica e devem seguir uma metodologia semiológica e diagnóstica a fim de diferenciar os processos produtivos dos não produtivos junto aos agentes envolvidos. Exames complementares como a ultrassonografia, punções guiadas e LTB ou LBA vêm auxiliando o buiatra na condução de diagnósticos mais precoces, além do estabelecimento de prognósticos e direcionamento da conduta terapêutica. Dada a natureza multifacetada dessas doenças, as práticas de gestão (ex.: melhorias de instalações e implementação de medidas de biossegurança) precisam ser consideradas para o controle e prevenção. Ainda, ressalta-se que as condições ambientais e fatores estressantes também desempenham papel crucial no desenvolvimento dessas doenças. Por fim, medidas de saúde adequadas, como protocolos vacinais, que melhoram a resposta imune do rebanho ajudam no controle e erradicação de certas enfermidades. 


\section{AGRADECIMENTOS}

Os autores agradecem ao comitê editorial da Revista Brasileira de Buiatria pela revisão e melhoria da versão final do manuscrito.

\section{MATERIAL SUPLEMENTAR}

Vídeos de distúrbios do trato respiratório inferior de pequenos ruminantes

\section{REFERÊNCIAS}

1. GONZÁLEZ, J.M., Financial aspects related to respiratory processes in lambs. In. SEOC MEETING ON RESPIRATORY MEDICINE IN LAMBS, 2000.Zaragoza.Anais...Zaragoza: p.17-50,2000.

2. GONZÁLEZ, J.M. Factores que condicionan la Supervivencia de los Corderos Tipo Ternasco. Estudio del Complejo Respiratorio Ovino. 2016. Tese (Doutorado) Universidad de Zaragoza,Zaragoza, Espanha.

3. McRAE, K.M. et al. Incidence and heritability of ovine pneumonia, and the relationship with production traits in New Zealand sheep. Small Ruminants Research,v.145,p.136-141,2016.

4. LACASTA, D. et al. Influence of climatic factors on the development of pneumonia in lambs. Small Ruminants Research,v.80,p.28-32,2008.

5. GOODWIN, K.A. et al. Pneumonic lesions in lambs in New Zealand: patterns of prevalence and effects on production. New Zealand Veterinary Journal, v.52,n.4,p.175-179, 2004.

6. ALLEY,M.R. The effect of chronic non-progressive pneumonia on weight gain of pasture-fed lambs. Nerw Zealand Veterinary Journal,v.35, n.10, p.163-166,1987.

7. GONZÁLEZ, J.M. et al. Lamb feedlot production in Spain: most relevant health issues. Small Ruminant Research,v.142, p.83-87,2016.

8. GREEN, L.E. et al. Lesions in finished early born lambs in southwest England and their relationship with age at slaughter. Preventive Veterinary Medicine, v.22,n.1-2,p.115-126, 1995.

9. LACASTA, D. et al. Significance of respiratory diseases in the health management of sheep. Small Ruminant Research,v.181,p.99-102,2019.

10. SUAREZ, V.H.; BUSETTI, M.R. Health management practices and disease prevalence in dairy sheep systems in Argentina. Pesquisa Veterinária Brasileira, v.29, n.11, p.931-937,2009.

11. MINGUIJÓN, E. et al. Small ruminant lentivirus infections and diseases. Veterinary Microbiology, v.181, n.1-2,p.75-89,2015.

12. HELMER, J.F. et al. Caracterização dos sistemas de produção de ovinos e caprinos na microrregião de Castanhal, Pará. Medicina Veterinária, v.14, n.3, p.202209,2020.

13. ALMEIDA,T.L.et al.Doenças de ovinos diagnosticadas no Laboratório de Anatomia Patológica Animal da Universidade Federal de Mato Grosso do Sul (1996-2010). Pesquisa Veterinária Brasileira, v.33, n.1, p.21-29,2013.

14. NUNES, J.S. et al. Enfermidades em ovinos necropsiados no hospital veterinário de Uberaba no período de 2007-2017. Psicologia e Saúde em Debate, v.5, supl.2,p.97-97,2019. 
15. ARAÚJO, M.R. et al. Ocorrência de pneumonia associada à infecção por Mannheimia haemolytica em ovinos de Minas Gerais. Pesquisa Veterinária Brasileira, v.29, n.9, p.719-724, 2009.

16. FARIAS, L. et al. Surto de mannheimiose pneumônica em ovinos no Sul do Brasil. Veterinária e Zootecnia, v.20, n.2, p.255-259,2013.

17. FRANCO, M.F. et al. Bacteria isolated from the lower respiratory tract of sheep and their relationship to clinical signs of sheep respiratory disease. Pesquisa Veterinária Brasileira,v.39, n.10, p.796-801,2019.

18. ROSA, F.B. et al. Doenças de caprinos diagnosticadas na região Central no Rio Grande do Sul: 114 casos. Pesquisa Veterinária Brasileira, v.33, n.2, p.199-204, 2013.

19. BASSUINO, D.M. et al. Causes of death in goats in Rio Grande do Sul state, Brazil: analysis of 322 cases (2000-2016). Pesquisa Veterinária Brasileira, v.38, n.11, p.2080-2087,2018.

20. COSENTINO, I.O. et al. Brote de mannheimiosis en caprinos: casos clínicos. In: CONGRESO NACIONAL Y INTERNACIONAL DE LA SOCIEDAD ESPAÑOLA DE OVINOTECNIA Y CAPRINOTECNIA (SEOC), 42, 28, 2018, Zaragoza.Anais...Zaragoza, 2018.

21. GONÇALVES, R.C. et al. Detection of serum antibodies to Parainfluenza type 3 Virus, Respiratory Syncytial Virus, Bovine Viral Diarrhea Virus, and Herpes Virus type 1 in sheep in the region of Botucatu, São Paulo - Brazil. African Journal of Agricultural Research, v.3, n.4,p.1-5, 2011.

22. FRANCO,M.F. et al. Indirect detection of respiratory viruses responsible for respiratory disease in she-
ep.Medicina Veterinária, v.14,n.1,p.7-13,2020.

23. YENER Z. et al. Immunohisto-chemical detection of Parainfluenza Type 3 Virus antigens in paraffin sections of pneumonic caprine lungs. Journal of Veterinary Medicine. A, Physiology, Pathology, Clinical Medicine.v.52,n.6,p.268-271,2005.

24. SHEEHAN M.et al. An aetiopathological study of chronic bronchopneumonia in lambs in Ireland. Veterinary Journal,v.173,n.3,p.630-637,2007.

25. CASTELLS, E. et al. Diagnostic imaging techniques of the respiratory tract of sheep. Small Ruminant Research,v.180,p.112-1262019.

26. MARCONDES, J.S. et al. Lavado traqueobrônquico por via nasotraqueal como metodologia de colheita de células do trato respiratório de ovinos sadios e portadores de afecções pulmonares. Pesquisa Veterinária Brasileira,v.31,n.4,p.281-286,2011.

27. JARIKRE, A.T. et al. Bronchoalveolar lavage fluid cellular and haematological changes in different types of caprine pneumonia. Nigerian Journal of Physiological Sciences, v.31,n.1, p.31-36,2016.

28. NAVARRO, T. et al. Epidemiology of ovine respiratory complex in lambs. Small Ruminant Research, v.179,p.70-74,2019.

29. NAVARRO, T. et al. Predisposing factors inducing ovine respiratory complex in intensive-reared lambs. Small Ruminant Research,v.180, p.106-111,2019.

30. MILLER, D.S. et al. Domestic sheep (Ovis aries) Pasteurellaceae isolates from diagnostic submissions to the Caine Veterinary Teaching Center (1990-2004). Veterinary Microbiology,v.150, n.3-4, p.284-288,2011. 
31. GLENDINNING, L.et al. Variability of the sheep lung microbiota. Applied and Environmental Microbiology,v.82, n.11, p.3225-3238, 2016.

32. BALARO, M.F.A. et al. Língua azul: desmistificando a doença. Revista Acadêmica Ciência Animal, v.15, supl.2,p.21-31,2017.

33. POLITIS, A.P. et al. Treatment of bacterial respiratory infections in lambs. Small Ruminant Research, v.176, p.70-75,2019.

34. SCOTT, P. Antibiotic treatment response of chronic lung diseases of adult sheep in the United Kingdom Based upon ultrasonographic findings. Veterinary Medicine International, v.2014,537501,2014.

35. GONZÁLEZ,J.M. et al. Prevention of Ovine Respiratory Complex in lambs based on vaccination. Small Ruminant Research,v.180,p.127-130,2019.

36. ORTÍN, A. et al. Ovine Pulmonary Adenocarcinoma: a transmissible lung cancer of sheep, difficult to control. Small Ruminant Research, v.176, p.37-41, 2019.

37.LONDONE, P. et al. Reporte de Adenocarcinoma Pulmonar Ovino en un cordero de cinco meses de edad en Puno. Revista de Investigaciones Veterinarias del Perú, v.25, n.4, p.545-550, 2014.

38. CARAVEO ROMERO, K.A. et al. Diagnosis of pulmonary adenocarcinoma (Jaagsiekte virus) in a sheep herd in Mexico. Revista Acadêmica: Ciência Animal,v.17, supl.1,p.404-407,2019.

39. DRIEMEIER, D. et al. Adenomatose pulmonar ("jaagsiekte") em ovino no Rio Grande de Sul. Ciência Rural,v.28, n.1,p.147-150,1998.
40. Balaro, M.F.A. 2021. Comunicação pessoal (Universidade Federal Fluminense).

41. DE LAS HERAS, M. et al. Pathology of ovine pulmonary adenocarcinoma. Current Topics in Microbiology and Immunology, v.275, p.25-54,2003.

42. SHARP, J.M.; DE LAS HERAS, M. Contagious Respiratory Tumours.In: MARTIN, W.B., AITKEN, I.D. $1^{\mathrm{a} e d}$. Diseases of Sheep. Oxford: Blackwell Science, p.181-186, 2000.

43. COUSENS, C. et al. Jaagsiekte sheep retrovirus is present at high concentration in lung fluid produced by ovine pulmonary adenocarcinoma-affected sheep and can survive for several weeks at ambient temperatures. Research in Veterinary Science, v.87, n.1, p.154-156, 2009.

44. VOIGT, K. et al. Eradication of ovine pulmonary adenocarcinoma by motherless rearing of lambs. Veterinary Record,v.161, n.4,p.129-132,2007.

45. COUSENS, C.; SCOTT, P.R. Assessment of transthoracic ultrasound diagnosis of ovine pulmonary adenocarcinoma in adult sheep. Veterinary Record, v.177,n.14,p.366, 2015.

46. BLOWEY, R.W.; WEAVER, A.D. Color Atlas of Diseases and Disorders of Cattle. ${ }^{\mathrm{a}} \mathrm{ed}$. Missouri: Elsevier, 2011.280p.

47. SCOTT, P.R. Lung auscultation recording from normal sheep and from sheep with well-defined respiratory tract pathology. Small Ruminant Research, v.92, p.104-107,2010.

48. SCOTT, P.R. Overview of aspiration pneumonia. MSD Veterinary Manual,2014. 
49. DARCY, H.P. et al. Retrospective analysis of incidence, clinical features, potential risk factors, and prognostic indicators for aspiration pneumonia in three brachycephalic dog breeds. Journal of the American Veterinary Medical Association, v.253, n.7,p.869-876, 2018.

50. LACASTA, D. et al. Gangrenous pneumonia, ovine respiratory complex and visceral form of caseous lymphadenitis: Relevance in lower respiratory tract disorders of adult sheep. Small Ruminant Research, v.180,p.100-105,2019.

51. PUGH, D.G.; BAIRD, A.N. Sheep and Goat Medicine. 2aed. Elsevier, Missouri: Elsevier, 2012. 640p.

52. SÁEZ, T. et al. Laryngeal hemiplegia in a ram associated with Sarcocystis species infection. Veterinary Record,v.153,n.1,p.27-28,2003.

53. ANTONIASSI, N.A.B. et al. Alterações clínicas e patológicas em ovinos infectados naturalmente pelo vírus da língua azul no Rio Grande do Sul. Pesquisa Veterinária Brasileira,v.30, n.12,p.1010-1016,2010.

54. AZIZI, S. et al. Pneumonia in slaughtered sheep in south-western Iran: pathological characteristics and aerobic bacterial aetiology. Veterinaria Italiana, v.49, n.1,p.109-118,2013.

55. BIESCAS, E. et al. AA Amyloidosis induced in sheep principally affects the gastrointestinal tract. Journal of Comparative Pathology, v.140, n.4, p.238246,2009.

56. MÉNSUA, C. et al. Pathology of AA amyloidosis in domestic sheep and goats. Veterinary Pathology, v.40, n.1,p.71-80,2003.

57. MINGUIJÓN, E. et al. Small ruminant lentivirus infections and diseases. Veterinary Microbiology, v.181, n.1-2,p.75-89,2015.

58. LUJÁN, L. et al. Pulmonary lentivirus infection in sheep. Small Ruminant Research,v.181, p.87-90,2019.

59. Azevedo, D.A.A.et al. Small ruminant lentiviruses: economic and productive losses, consequences of the disease. Arquivos do Instituto Biológico, v.84, e0552016, 2018 .

60. PINHEIRO, R.R. et al. Lentiviroses em pequenos ruminantes: principais métodos de diagnóstico. Sobral: Embrapa Caprinos e Ovinos, 2012.42p.

61. KONISHI, M. et al. Combined eradication strategy for CAE in dairy goat farm in Japan. Small Ruminant Research,v.99, p.65-71,2011.

62. FONTAINE, M.C.; BAIRD, G.J. Caseous lymphadenitis. Small Ruminant Research,v.76, p.42-48, 2008.

63. WINDSOR, P.A.; BUSH, R.D. Caseous lymphadenitis: Present and near forgotten from persistent vaccination? Small Ruminant Research, v.142, p.6-10, 2016.

64. RUIZ, H. et al. The relevance of caseous lymphadenitis as a cause of culling in adult sheep.Animals, v.10, a.1962,2020.

65. SOUZA, M.F. et al. Linfadenite caseosa em ovinos deslanados abatidos em um frigorífico da Paraíba. Pesquisa Veterinária Brasileira, v.31, n.3, p.224-230, 2011.

66. MACHADO, G. et al. Linfadenite caseosa em ovinos abatidos sob inspeção federal no estado do Rio Grande do Sul - estimativas de perdas. Acta Scientiae 
Veterinariae, v.39, n.2,a.967,2011.

67. BARNABÉ, N.N.C. et al. Characterization of caseous lymphadenitis in caprine animals slaughtered in a semi-arid region of Brazil. Semina: Ciências Agrárias, v.40, n.5, p.1867-1878, 2019.

68. WINDSOR, P.A. Control of caseous lymphadenitis. Veterinary Clinics of North America: Food Animal Practice,v.27,n.1,p.193-202, 2011.

69. LACASTA, D. et al. Vaccination schedules in small ruminant farms. Veterinary Microbiology, v.181, n.1-2, p.34-46,2015.

70. CHAKRABORTY, S. et al. Advances in diagnosis of respiratory diseases of small ruminants. Veterinary Medicine International,v.2014,508304, 2014.

71. YATOO, M.I. et al. Mycoplasmosis in small ruminants in India: a review. Journal of Experimental Biology and Agricultural Sciences, v.6, n. 2, p.264-281,2018.

72. HANDELAND, K. et al. Mycoplasma ovipneumoniae - A primary cause of severe pneumonia epizootics in the Norwegian Muskox (Ovibos moschatus) Population.PLoS ONE,v.9, n.9, e106116, 2014.

73. FILIOUSSIS, G. et al. Congenital polyarthritis in goat kids attributed to Mycoplasma agalactiae. Veterinary Record,v.169,n.12,p.364,2011.

74. SILVA, N.S. et al. Infecção congênita em cabritos por Mycoplasma agalactiae. Arquivo Brasileiro de Medicina Veterinária e Zootecnia, v.66, n.2, p.631-634,2014.

75. PEIXOTO, R.M. et al. Mycoplasma agalactiae em rebanhos leiteiros no estado do Ceará em associação com o vírus da artrite encefalite caprina. Acta Scientiae Veterinariae, v.46, a.1533,2018.
76. DI PROVVIDO, A. et al. Mycoplasma pneumonia in small ruminants: A ten-year long retrospective survey. Small Ruminant Research,v.153,p.103-106,2017.

77. SANTOS, S.B. et al. Epidemiology of Mycoplasma agalactiae and Mycoplasma mycoides cluster in flocks of northeastern Brazil. Ciência Rural, v.48, n.4, e20170427,2018.

78. FERNÁNDEZ, S. et al. Investigations into the seasonal presence of Mycoplasma species in fattening lambs. VeterinaryJournal,v.212,p.80-82,2016.

79. DAEE, A.A. et al. Identification of Mycoplasma ovipneumoniae and Mycoplasma arginini in sheep with pneumonia in north east of Iran. Iranian Journal of Veterinary Research,v.21, n.1,p.15-19,2020.

80. DASSANAYAKE, R.P. et al. Mycoplasma ovipneumoniae can predispose bighorn sheep to fatal Mannheimia haemolytica pneumonia. Veterinary Microbiology, v.145, n.3-4,p.354-359, 2010.

81. TAYLOR, M. et al. Veterinary Parasitology. 4aed. Oxford:Wiley-Blackwell,2015.1032p

82. ENGDAW,T.A. A review on: lungworm infection in small ruminants. World Journal of Pharmaceutical and Life Sciences, v.1,n.3,p.149-159,2015.

83. OYDA, S.; MEKURIA, A. Review on lungworm infection in sheep and goats in Ethiopia.Journal of Biology, Agriculture and Healthcare, v.8, n.11, p.15-20, 2018.

84. SNYDER, P.W.N. et al. Comparison of modified flotac and baermann techniques for quantifying lungworm larvae in free-ranging bighorn sheep (Ovis canadensis) feces, Montana, USA. Journal of Wildlife Diseases, v.51,n.4, p.843-848, 2015. 
85. SEKIYA, M. et al. Bulk milk ELISA and the diagnosis of parasite infections in dairy herds: a review. Irish Veterinary Journal,v.66, n.1,p.14,2013.

86. ASMARE, K. et al. Lungworm infection in small ruminants in Ethiopia: systematic review and metaanalysis. Veterinary Parasitology: Regional Studies and Reports, v.14,p.63-70,2018

87. CARMO, P.M.S.D. et al. Conidiobolomycosis, cryptococcosis, and aspergillosis in sheep and goats: a review. Journal of Veterinary Diagnostic Investigation, v.32, n.6, p.826-834,2020.

88. McMICHAEL, M. Fungal pneumonia in animals. MSD Veterinary Manual,2020.

89. ELAD, D.; SEGAL, E. Diagnostic aspects of veterinary and human aspergillosis. Frontiers in Microbio$\log y$, v.9, p.1303, 2018.

90. AUSTWICK, P.K. et al. Pulmonary aspergillosis in lambs. Veterinary Record,v.72, n.2,p.19-21,1960.

91. OHSHIMA, K. et al. Pathological studies on mucormycoses of the forestomach and abomasums in ruminants: a report on six cases complicated with candidiasis or pulmonary aspergillosis. Japanese Journal of Veterinary Science, v.38, n.33, p.269-280,1976.

92. GONZALEZ,J.F. et al.Pulmonary aspergillosis in young lambs. Revista Iberoamericana de Micología, v.10, n.4,p.98-99,1993.

93. MANDAL, P.C.; GUPTA, P.P. Sequential pathological studies in goats infected intratracheally with Aspergillus fumigatus. Mycopathologia, v.121, n.2, p.7781,1993.

94. MAHMOUD, M.A. et al. Prevalence of some res- piratory diseases among sheep and goats in Shalateen, Halaieb and Abu-Ramad areas. Journal of Veterinary MedicalResearch,v.15, n.2,p.196-202,2005.

95. RIZZO, H. et al. Aspergillus fumigatus em pulmão de ovino no Brasil - relato de caso. Revista Brasileira de Medicina Veterinária,v.38, n.4,p.413-419,2016.

96. PÉREZ, V. et al. Generalized aspergillosis in dairy sheep. Journal of Veterinary Medicine, Series B, v.46, n.9, p.613-621, 1999. 